\title{
Novel empirical model for predicting residual flexural capacity of corroded steel reinforced concrete beam
}

\author{
Zhao-Hui LU ${ }^{\mathrm{a}, \mathrm{b}}$, Hong-Jun WANG ${ }^{\mathrm{b}}$, Fulin QU' ${ }^{\mathrm{c}}$, Yan-Gang ZHAO ${ }^{\mathrm{a}}$, Peiran $\mathrm{LI}^{\mathrm{c}}$, Wengui LI $^{\mathbf{c}^{*}}$ \\ ${ }^{a}$ Key Laboratory of Urban Security and Disaster Engineering of Ministry of Education, Beijing University of Technology, Beijing \\ 100124, China \\ ${ }^{b}$ School of Civil Engineering, Central South University, Changsha 410075, China \\ ${ }^{c}$ School of Civil and Environmental Engineering, University of Technology Sydney, NSW 2007, Australia \\ *Corresponding author.E-mail: wengui.li@uts.edu.au
}

(C) Higher Education Press 2020

\begin{abstract}
In this study, a total of 177 flexural experimental tests of corroded reinforced concrete (CRC) beams were collected from the published literature. The database of flexural capacity of CRC beam was established by using unified and standardized experimental data. Through this database, the effects of various parameters on the flexural capacity of CRC beams were discussed, including beam width, the effective height of beam section, ratio of strength between longitudinal reinforcement and concrete, concrete compressive strength, and longitudinal reinforcement corrosion ratio. The results indicate that the corrosion of longitudinal reinforcement has the greatest effect on the residual flexural capacity of CRC beams, while other parameters have much less effect. In addition, six available empirical models for calculating the residual flexural strength of CRC beams were also collected and compared with each other based on the established database. It indicates that though five of six existing empirical models underestimate the flexural capacity of CRC beams, there is one model overestimating the flexural capacity. Finally, a newly developed empirical model is proposed to provide accurate and effective predictions in a large range of corrosion ratio for safety assessment of flexural failure of CRC beams confirmed by the comparisons.
\end{abstract}

KEYWORDS CRC beams, flexural capacity, steel corrosion, database, empirical models

\section{Introduction}

Presently, the durability problem of reinforced concrete $(\mathrm{RC})$ beams has attracted more and more attention all over the world. Among the many causes of durability damage of beams, premature failure of beams caused by reinforcement corrosion is one of the biggest threats currently faced by the RC industry [1]. Identifying and quantifying the impacts of deteriorating on the residual bearing capacity of $\mathrm{RC}$ beams can provide the currently used inspection procedures with lots of strategic and cost-effective rehabilitation methods [2]. Therefore, many researchers have been devoted to investigate the residual strength and performance of corroded reinforced concrete (CRC) beams. Almusallam et al. [3] studied the effect of reinforcement corrosion on flexural behavior of $\mathrm{RC}$ slabs; Rodriguez et al. [4] tested the bending resistance of CRC beams with different reinforcement ratios, stirrup spacing and corrosion rate. Mangat and Elgarf [5] conducted an experimental study on 111 CRC beams and studied the effect of corrosion on their residual bending strength; Hui et al. [6] conducted an experimental study on the failure modes and residual flexural capacity of CRC beams, in which the chloride ingression was accelerated by sodium chloride $\left(\mathrm{CaCl}_{2}\right)$ in the concrete; and Huang and Yang [7] evaluated the effect of corrosion on RC beams and assessed the structural behavior of CRC beams.

Meanwhile, there are still many other previous similar studies [8-20]. The effect of reinforcement corrosion on CRC beams mainly includes the following three aspects: 
for steel reinforcement, the cross-sectional area will be reduced to change the mechanical properties $[8,9,11-14]$; for concrete, the concrete cover of the beam is longitudinally cracked or even peeled off because of the volume expansion of the steel corrosion products, resulting in a decrease in the effective area of the concrete $[10,15]$; for the bond performance between concrete and steel, a loose rust layer is formed at the interface between concrete and steel because of the steel corrosion, which reduces the mechanical bite force between concrete and steel [16-20]. Therefore, the bond performance between concrete and steel will degenerate as the steel corrosion increases. As mentioned above, the flexural performance and residual strength of CRC beams decrease due to the steel corrosion in concrete.

For the prediction of the residual flexural strength of CRC beams, many existing empirical models [21-27] have been proposed. Existing empirical models include two main calculation methods when calculating the residual flexural strength of CRC beams. On one hand, on the basis of the experimental data, the ultimate bending moment of CRC beams is calculated according to the corresponding specifications at first, and then the calculated ultimate bending moment is multiplied by a reduction factor by considering the influence of the corrosion [21,25-27]; on the other hand, considering the corrosion influence, the yield stress of the longitudinal steel reinforcement is multiplied by a reduction factor and the effective crosssectional area of the steel bars is considered, and then the ultimate bending moment of the CRC beams is calculated according to the corresponding specifications [22-24]. To obtain CRC beam members, there are currently three main methods [23]: rapid corrosion member experimental (electrochemical corrosion and chlorinated salt corrosion) $[28,29]$, natural exposed experiment $[6,11,30]$ and damaged component test removed by actual engineering. To achieve the expected results in the short-term, most of the current models generally utilize laboratory energization to accelerate corrosion.

Although existing empirical models [22-27] can somehow predict the residual flexural capacity of the CRC beams, these existing empirical models exhibit certain deviations in the prediction when the test data is from other experiments and the rate of the steel corrosion varies. In other words, most of the existing empirical models become less accurate in different cases. Meanwhile, there is less comparative analysis of the empirical models in the previous studies. Therefore, the main purpose of this study is to introduce existing empirical models for calculating the residual flexural strength of CRC beams, and to compare and analyze existing empirical models through the unified and standardized experimental database. In addition, based on the model of corrosion-induced bond strength degradation [31] and existing specifications $[32,33]$, a new prediction model for the residual flexural strength of CRC beams is proposed to accurately predict the residual flexural capacity of the CRC beams through the comparative analysis of the test database.

\section{Experimental database of flexural capacity of CRC beams}

\subsection{Establishment of experimental database}

In this section, experimental data of 177 sets of CRC beams subjected to concentrated loads with residual flexural capacity are collected from published literature [4,6,18,25,26,34-38], including Jin and Zhao [18], 17 sets; Hui et al. [6], 24 sets; Cao et al. [34], 12 sets; Xia et al. [35], 20 sets; Azad et al. [25], 24 sets; Azad et al. [26], 36 sets; Shang [36], 8 sets; Rodriguez et al. [4], 16 sets; Chen [37], 7 sets; and Zhang [38], 13 sets. These collected experimental data are integrated to establish an experimental database and are listed in Table 1. The concrete compressive strength $\left(f_{\mathrm{cyl}, 150}\right.$ and $f_{\mathrm{cyl}, 75}$ correspond to the uniaxial compressive strength determined from cylinder tests of $150 \mathrm{~mm} \times 300 \mathrm{~mm}$ specimens and $75 \mathrm{~mm} \times$ $150 \mathrm{~mm}$ specimens, respectively; and $f_{\mathrm{cu}, 150}$ is the uniaxial compressive strength determined from cube tests of 150 $\mathrm{mm}$ specimens), width of beam section $(b)$, depth of beam section $(h)$, section ratio of longitudinal steel reinforcement $\left(\rho_{l}\right)$, shear span-to-depth ratio of beam $(\lambda)$, corrosion degree of longitudinal reinforcement $\left(\eta_{\mathrm{wt}}\right.$ and $\eta_{\mathrm{sn}}$ are the corrosion ratios which express as weight loss ratio and the section loss ratio of longitudinal reinforcement, respectively), ultimate flexural strength from tests at failure $\left(M_{\mathrm{fx}, \mathrm{exp}}\right)$, and ultimate concentrated load from tests at failure $P_{\text {fx,exp }}$ are all summarized in Table 1. Important characteristics of the selected experimental CRC beams are summarized as follows.

1) The width of test beams $b$ varies from 120 to $200 \mathrm{~mm}$, and the depth of beam $h$ varies from 150 to $315 \mathrm{~mm}$. The shear span-to-depth ratio of beam $\lambda$ ranges from 1.35 to 4.88 , including both slender $(\lambda \geqslant 2.5)$ and deep beams $(\lambda<2.5)[39]$.

2) The cube compressive strength of concrete $\left(f_{\mathrm{cu}, 150}\right)$ of test beams varies from 22.13 to $62.62 \mathrm{MPa}$, which includes ordinary concrete and high-strength concrete according to GB50010-2002 (Design code for concrete structures) [33]; and the yield strength of the longitudinal reinforcements varies between 297 and $593 \mathrm{MPa}$.

3) The corrosion ratio which expresses as weight loss ratio of longitudinal reinforcement of test beams varies between 0 and $34.8 \%$, and the corrosion ratio which expresses as section loss ratio of longitudinal reinforcement of test beams varies between 0 and $47.77 \%$.

\subsection{Conversion relations of compressive strength of concrete}

When calculating the flexural capacity of CRC beams, the 
Table 1 Experimental data of flexural tests for CRC beams

\begin{tabular}{|c|c|c|c|c|c|c|c|c|c|c|c|}
\hline literature & specimen & $\begin{array}{c}\text { concrete } \\
\text { strength } \\
(\mathrm{MPa})\end{array}$ & $\begin{array}{c}b \\
(\mathrm{~mm})\end{array}$ & $\begin{array}{c}h \\
(\mathrm{~mm})\end{array}$ & $\begin{array}{c}\rho_{1} \\
(\%)\end{array}$ & $\begin{array}{c}\varepsilon_{\mathrm{y}} \\
(\mathrm{MPa})\end{array}$ & $\bar{\lambda}$ & $\begin{array}{l}\eta_{\mathrm{wt}} \\
(\%)\end{array}$ & $\begin{array}{l}\eta_{\mathrm{sn}} \\
(\%)\end{array}$ & $\begin{array}{c}M_{\mathrm{fx}, \exp } \\
(\mathrm{kN} \cdot \mathrm{m})\end{array}$ & $\begin{array}{c}P_{\mathrm{fx}, \mathrm{exp}} \\
(\mathrm{kN})\end{array}$ \\
\hline \multirow{17}{*}{$\begin{array}{l}\text { Jin and Zhao } \\
{[18]} \\
(17 \text { tests })\end{array}$} & BD1 & 22.13 & 150 & 150 & 1.33 & 427 & 2.65 & 0.47 & 1.76 & 10.27 & 34.23 \\
\hline & $\mathrm{BD} 2$ & 22.13 & 150 & 150 & 1.33 & 427 & 2.65 & 0.54 & 1.83 & 9.53 & 31.77 \\
\hline & BD3 & 22.13 & 150 & 150 & 1.33 & 427 & 2.65 & 1.21 & 2.49 & 9.92 & 33.07 \\
\hline & BD4 & 22.13 & 150 & 150 & 1.33 & 427 & 2.65 & 1.24 & 2.52 & 9.32 & 31.07 \\
\hline & BD5 & 22.13 & 150 & 150 & 1.33 & 427 & 2.65 & 1.24 & 2.52 & 10.27 & 34.23 \\
\hline & BD6 & 22.13 & 150 & 150 & 1.33 & 427 & 2.65 & 1.27 & 2.55 & 9.53 & 31.77 \\
\hline & BD7 & 22.13 & 150 & 150 & 1.33 & 427 & 2.65 & 2.15 & 3.42 & 9.53 & 31.77 \\
\hline & BD8 & 22.13 & 150 & 150 & 1.33 & 427 & 2.65 & 2.82 & 4.08 & 9.07 & 30.23 \\
\hline & BD9 & 22.13 & 150 & 150 & 1.33 & 427 & 2.65 & 2.83 & 4.09 & 9.53 & 31.77 \\
\hline & BD10 & 22.13 & 150 & 150 & 1.33 & 427 & 2.65 & 2.88 & 4.14 & 8.69 & 28.97 \\
\hline & BD11 & 22.13 & 150 & 150 & 1.33 & 427 & 2.65 & 3.45 & 4.71 & 9.53 & 31.77 \\
\hline & BD12 & 22.13 & 150 & 150 & 1.33 & 427 & 2.65 & 4.14 & 5.39 & 8.20 & 27.33 \\
\hline & BD13 & 22.13 & 150 & 150 & 1.33 & 427 & 2.65 & 5.20 & 6.43 & 8.69 & 28.97 \\
\hline & BD14 & 22.13 & 150 & 150 & 1.33 & 427 & 2.65 & 6.05 & 7.27 & 7.89 & 26.30 \\
\hline & BDU1 & 22.13 & 150 & 150 & 1.33 & 427 & 2.65 & 0.47 & 1.76 & 9.91 & 33.03 \\
\hline & BDU2 & 22.13 & 150 & 150 & 1.33 & 427 & 2.65 & 4.85 & 6.09 & 8.56 & 28.53 \\
\hline & BDU3 & $22.13\left(f_{\mathrm{cu}, 150}\right)$ & 150 & 150 & 1.33 & 427 & 2.65 & 5.58 & 6.81 & 8.32 & 27.73 \\
\hline \multirow{24}{*}{$\begin{array}{l}\text { Hui et al. [6] } \\
\text { (24 tests) }\end{array}$} & A 01 & 39.4 & 151 & 252 & 0.90 & 397 & 3.1 & 0.00 & 0.00 & 26.14 & 37.34 \\
\hline & A 02 & 39.4 & 158 & 251 & 0.89 & 397 & 3.2 & 0.00 & 0.00 & 26.49 & 37.84 \\
\hline & A21 & 39.6 & 154 & 255 & 0.92 & 383 & 3.2 & 7.11 & 8.32 & 21.84 & 31.20 \\
\hline & $\mathrm{A} 22$ & 39.6 & 158 & 257 & 0.87 & 378 & 3.1 & 10.17 & 15.65 & 22.19 & 31.70 \\
\hline & A 31 & 38.1 & 176 & 250 & 0.79 & 381 & 3.2 & 4.60 & 5.84 & 22.40 & 32.00 \\
\hline & $\mathrm{A} 32$ & 38.1 & 176 & 253 & 0.80 & 382 & 3.2 & 8.49 & 9.68 & 24.21 & 34.59 \\
\hline & B01 & 39.4 & 153 & 251 & 1.19 & 402 & 3.2 & 0.00 & 0.00 & 33.70 & 48.14 \\
\hline & B02 & 39.4 & 156 & 253 & 1.15 & 402 & 3.1 & 0.00 & 0.00 & 33.74 & 48.20 \\
\hline & B11 & 35.0 & 160 & 254 & 1.14 & 495 & 3.2 & 3.60 & 4.85 & 30.20 & 43.14 \\
\hline & B12 & 35.0 & 156 & 252 & 1.20 & 410 & 3.3 & 2.20 & 3.47 & 30.90 & 44.14 \\
\hline & B21 & 36.6 & 173 & 250 & 1.10 & 395 & 3.3 & 4.49 & 5.73 & 28.45 & 40.64 \\
\hline & B22 & 36.6 & 154 & 254 & 1.20 & 396 & 3.2 & 3.99 & 5.24 & 29.78 & 42.54 \\
\hline & B31 & 31.4 & 166 & 253 & 1.12 & 396 & 3.2 & 5.40 & 6.63 & 30.55 & 43.64 \\
\hline & B32 & 31.4 & 158 & 251 & 1.18 & 393 & 3.2 & 4.20 & 5.45 & 29.50 & 42.14 \\
\hline & $\mathrm{C} 01$ & 39.4 & 168 & 252 & 1.40 & 381 & 3.3 & 0.00 & 0.00 & 38.95 & 55.64 \\
\hline & $\mathrm{C} 02$ & 34.6 & 159 & 254 & 1.45 & 381 & 3.2 & 2.33 & 3.60 & 36.85 & 52.64 \\
\hline & $\mathrm{C} 21$ & 34.4 & 156 & 253 & 1.52 & 376 & 3.3 & 3.33 & 4.59 & 31.95 & 45.64 \\
\hline & $\mathrm{C} 22$ & 34.4 & 166 & 256 & 1.40 & 380 & 3.2 & 4.65 & 5.89 & 35.45 & 50.64 \\
\hline & D01 & 39.4 & 163 & 251 & 0.85 & 297 & 3.2 & 0.00 & 0.00 & 23.20 & 33.14 \\
\hline & D02 & 39.4 & 164 & 250 & 0.83 & 297 & 3.1 & 0.00 & 0.00 & 23.20 & 33.14 \\
\hline & D21 & 34.4 & 172 & 252 & 0.80 & 293 & 3.1 & 10.99 & 16.42 & 17.74 & 25.34 \\
\hline & D22 & 34.4 & 158 & 252 & 0.90 & 303 & 3.2 & 9.68 & 10.85 & 17.95 & 25.64 \\
\hline & E01 & 35.6 & 155 & 249 & 0.63 & 494 & 3.0 & 0.00 & 0.00 & 26.00 & 37.14 \\
\hline & E02 & $34.4\left(f_{\mathrm{cu}, 150}\right)$ & 172 & 255 & 0.58 & 494 & 3.1 & 8.82 & 10.01 & 21.45 & 30.64 \\
\hline
\end{tabular}




\begin{tabular}{|c|c|c|c|c|c|c|c|c|c|c|c|}
\hline \multirow[b]{2}{*}{ literature } & \multirow[b]{2}{*}{ specimen } & \multirow[b]{2}{*}{$\begin{array}{c}\text { concrete } \\
\text { strength } \\
(\mathrm{MPa})\end{array}$} & \multirow[b]{2}{*}{$\begin{array}{c}b \\
(\mathrm{~mm})\end{array}$} & \multirow[b]{2}{*}{$\begin{array}{c}h \\
(\mathrm{~mm})\end{array}$} & \multirow[b]{2}{*}{$\begin{array}{c}\rho_{1} \\
(\%)\end{array}$} & \multirow[b]{2}{*}{$\begin{array}{c}\varepsilon_{\mathrm{y}} \\
(\mathrm{MPa})\end{array}$} & \multirow[b]{2}{*}{$\lambda$} & \multirow[b]{2}{*}{$\begin{array}{l}\eta_{\mathrm{wt}} \\
(\%)\end{array}$} & \multirow[b]{2}{*}{$\begin{array}{l}\eta_{\mathrm{sn}} \\
(\%)\end{array}$} & \multicolumn{2}{|c|}{ (Continued) } \\
\hline & & & & & & & & & & $\begin{array}{c}M_{\mathrm{fx}, \exp } \\
(\mathrm{kN} \cdot \mathrm{m})\end{array}$ & $\begin{array}{c}P_{\mathrm{fx}, \exp } \\
(\mathrm{kN})\end{array}$ \\
\hline \multirow{12}{*}{$\begin{array}{l}\text { Cao et al. } \\
{[34]} \\
(12 \text { tests })\end{array}$} & RCBD12(1) & 34.4 & 120 & 200 & 1.08 & 470 & 2.78 & 0.00 & 0.00 & 20.53 & 41.06 \\
\hline & RCBD12(2) & 34.4 & 120 & 200 & 1.08 & 470 & 2.78 & 2.16 & 3.43 & 18.50 & 37.00 \\
\hline & RCBD12(3) & 34.4 & 120 & 200 & 1.08 & 470 & 2.78 & 4.19 & 5.44 & 17.34 & 34.68 \\
\hline & RCBD12(4) & 34.4 & 120 & 200 & 1.08 & 470 & 2.78 & 6.72 & 7.93 & 15.18 & 30.36 \\
\hline & RCBD12(5) & 34.4 & 120 & 200 & 1.08 & 470 & 2.78 & 9.31 & 10.49 & 14.50 & 29.00 \\
\hline & RCBD12(6) & 34.4 & 120 & 200 & 1.08 & 470 & 2.78 & 13.05 & 18.35 & 12.90 & 25.80 \\
\hline & RCBD14(1) & 34.4 & 120 & 200 & 1.48 & 500 & 2.78 & 0.00 & 0.00 & 26.73 & 53.46 \\
\hline & RCBD14(2) & 34.4 & 120 & 200 & 1.48 & 500 & 2.78 & 2.36 & 3.63 & 24.60 & 49.20 \\
\hline & RCBD14(3) & 34.4 & 120 & 200 & 1.48 & 500 & 2.78 & 4.47 & 5.71 & 22.40 & 44.80 \\
\hline & RCBD14(4) & 34.4 & 120 & 200 & 1.48 & 500 & 2.78 & 6.29 & 7.51 & 20.70 & 41.40 \\
\hline & RCBD14(5) & 34.4 & 120 & 200 & 1.48 & 500 & 2.78 & 9.58 & 10.76 & 19.50 & 39.00 \\
\hline & \multicolumn{2}{|c|}{$\operatorname{RCBD} 14(6) 34.4\left(f_{\mathrm{cu}, 150}\right)$} & 120 & 200 & 1.48 & 500 & 2.78 & 12.34 & 17.69 & 18.10 & 36.20 \\
\hline \multirow{20}{*}{$\begin{array}{l}\text { Xia et al. } \\
{[35]} \\
(20 \text { tests) }\end{array}$} & BAI-0 & 25.9 & 150 & 200 & 1.49 & 425 & 2.06 & 0.00 & 0.00 & 22.68 & 64.80 \\
\hline & BAI-1 & 25.9 & 150 & 200 & 1.49 & 425 & 2.06 & 1.80 & 3.25 & 22.24 & 63.54 \\
\hline & BAI-2 & 25.9 & 150 & 200 & 1.49 & 425 & 2.06 & 3.09 & 4.5 & 21.63 & 61.80 \\
\hline & BAI-3 & 25.9 & 150 & 200 & 1.49 & 425 & 2.06 & 3.80 & 5.19 & 20.65 & 59.00 \\
\hline & BAI-4 & 25.9 & 150 & 200 & 1.49 & 425 & 2.06 & 5.64 & 6.97 & 20.84 & 59.54 \\
\hline & BAI-5 & 25.9 & 150 & 200 & 1.49 & 425 & 2.06 & 6.07 & 7.39 & 21.37 & 61.06 \\
\hline & BAI-6 & 25.9 & 150 & 200 & 1.49 & 425 & 2.06 & 7.08 & 8.37 & 20.00 & 57.14 \\
\hline & BAI-7 & 25.9 & 150 & 200 & 1.49 & 425 & 2.06 & 8.67 & 9.91 & 20.84 & 59.54 \\
\hline & BAI-8 & 25.9 & 150 & 200 & 1.49 & 425 & 2.06 & 8.85 & 10.08 & 19.22 & 54.91 \\
\hline & BAI-9 & 25.9 & 150 & 200 & 1.49 & 425 & 2.06 & 10.36 & 11.55 & 18.34 & 52.40 \\
\hline & BBII-0 & 35.6 & 150 & 200 & 1.72 & 575 & 2.06 & 0.00 & 0.00 & 38.50 & 110.00 \\
\hline & BBII-1 & 35.6 & 150 & 200 & 1.72 & 575 & 2.06 & 1.45 & 2.91 & 36.75 & 105.00 \\
\hline & BBII-2 & 35.6 & 150 & 200 & 1.72 & 575 & 2.06 & 1.84 & 3.28 & 35.00 & 100.00 \\
\hline & BBII-3 & 35.6 & 150 & 200 & 1.72 & 575 & 2.06 & 2.64 & 4.06 & 34.48 & 98.51 \\
\hline & BBII-4 & 35.6 & 150 & 200 & 1.72 & 575 & 2.06 & 3.75 & 5.14 & 35.04 & 100.11 \\
\hline & BBII-5 & 35.6 & 150 & 200 & 1.72 & 575 & 2.06 & 5.26 & 6.6 & 35.88 & 102.51 \\
\hline & BBII-6 & 35.6 & 150 & 200 & 1.72 & 575 & 2.06 & 5.84 & 7.16 & 33.08 & 94.51 \\
\hline & BBII-7 & 35.6 & 150 & 200 & 1.72 & 575 & 2.06 & 7.37 & 8.65 & 34.39 & 98.26 \\
\hline & BBII-8 & 35.6 & 150 & 200 & 1.72 & 575 & 2.06 & 7.76 & 9.03 & 34.48 & 98.51 \\
\hline & BBII-9 & $35.6\left(f_{\mathrm{cu}, 150}\right)$ & 150 & 200 & 1.72 & 575 & 2.06 & 8.98 & 10.21 & 32.13 & 91.80 \\
\hline
\end{tabular}




\begin{tabular}{|c|c|c|c|c|c|c|c|c|c|c|c|}
\hline \multirow[b]{2}{*}{ literature } & \multirow[b]{2}{*}{ specimen } & \multirow[b]{2}{*}{$\begin{array}{c}\text { concrete } \\
\text { strength } \\
(\mathrm{MPa})\end{array}$} & \multirow[b]{2}{*}{$\begin{array}{c}b \\
(\mathrm{~mm})\end{array}$} & \multirow[b]{2}{*}{$\begin{array}{c}h \\
(\mathrm{~mm})\end{array}$} & \multirow[b]{2}{*}{$\begin{array}{c}\rho_{1} \\
(\%)\end{array}$} & \multirow[b]{2}{*}{$\begin{array}{c}\varepsilon_{\mathrm{y}} \\
(\mathrm{MPa})\end{array}$} & \multirow[b]{2}{*}{$\lambda$} & \multirow[b]{2}{*}{$\begin{array}{l}\eta_{\mathrm{wt}} \\
(\%)\end{array}$} & \multirow[b]{2}{*}{$\begin{array}{l}\eta_{\mathrm{sn}} \\
(\%)\end{array}$} & \multicolumn{2}{|c|}{ (Continued) } \\
\hline & & & & & & & & & & $\begin{array}{c}M_{\mathrm{fx}, \exp } \\
(\mathrm{kN} \cdot \mathrm{m})\end{array}$ & $\begin{array}{c}P_{\mathrm{fx}, \exp } \\
(\mathrm{kN})\end{array}$ \\
\hline \multirow{36}{*}{$\begin{array}{l}\text { Azad et al. } \\
{[26]} \\
(36 \text { tests) }\end{array}$} & B1-1 & 28 & 200 & 215 & 1.26 & 593 & 2.20 & 3.50 & 4.75 & 31.50 & 90.00 \\
\hline & B1-2 & 28 & 200 & 215 & 1.26 & 593 & 2.20 & 6.00 & 7.22 & 28.18 & 80.51 \\
\hline & B1-3 & 28 & 200 & 215 & 1.26 & 593 & 2.20 & 4.13 & 5.38 & 18.38 & 52.51 \\
\hline & B1-4 & 28 & 200 & 215 & 1.26 & 593 & 2.20 & 15.85 & 20.98 & 22.40 & 64.00 \\
\hline & B1-5 & 28 & 200 & 215 & 1.26 & 593 & 2.20 & 2.95 & 4.21 & 30.98 & 88.51 \\
\hline & B1-6 & 28 & 200 & 215 & 1.26 & 593 & 2.20 & 15.83 & 20.96 & 17.33 & 49.51 \\
\hline & B2-1 & 28 & 200 & 265 & 0.96 & 593 & 1.67 & 11.82 & 17.20 & 36.58 & 104.51 \\
\hline & B2-2 & 28 & 200 & 265 & 0.96 & 593 & 1.67 & 9.86 & 11.03 & 40.95 & 117.00 \\
\hline & B2-3 & 28 & 200 & 265 & 0.96 & 593 & 1.67 & 18.74 & 23.70 & 24.33 & 69.51 \\
\hline & B2-4 & 28 & 200 & 265 & 0.96 & 593 & 1.67 & 17.53 & 22.56 & 26.95 & 77.00 \\
\hline & B2-5 & 28 & 200 & 265 & 0.96 & 593 & 1.67 & 25.53 & 35.14 & 26.60 & 76.00 \\
\hline & B2-6 & 28 & 200 & 265 & 0.96 & 593 & 1.67 & 25.81 & 35.38 & 20.48 & 58.51 \\
\hline & B3-1 & 28 & 200 & 315 & 0.78 & 593 & 1.35 & 13.34 & 18.63 & 37.63 & 107.51 \\
\hline & B3-2 & 28 & 200 & 315 & 0.78 & 593 & 1.35 & 17.85 & 22.86 & 36.05 & 103.00 \\
\hline & B3-3 & 28 & 200 & 315 & 0.78 & 593 & 1.35 & 6.02 & 7.24 & 52.50 & 150.00 \\
\hline & B3-4 & 28 & 200 & 315 & 0.78 & 593 & 1.35 & 5.84 & 7.06 & 55.30 & 158.00 \\
\hline & B3-5 & 28 & 200 & 315 & 0.78 & 593 & 1.35 & 26.29 & 35.80 & 35.70 & 102.00 \\
\hline & B3-6 & 28 & 200 & 315 & 0.78 & 593 & 1.35 & 4.63 & 5.87 & 57.58 & 164.51 \\
\hline & B4-1 & 28 & 200 & 215 & 1.61 & 575 & 2.20 & 5.28 & 6.51 & 33.60 & 96.00 \\
\hline & B4-2 & 28 & 200 & 215 & 1.61 & 575 & 2.20 & 9.40 & 10.58 & 22.23 & 63.51 \\
\hline & B4-3 & 28 & 200 & 215 & 1.61 & 575 & 2.20 & 11.27 & 16.68 & 22.75 & 65.00 \\
\hline & B4-4 & 28 & 200 & 215 & 1.61 & 575 & 2.20 & 12.26 & 17.61 & 23.10 & 66.00 \\
\hline & B4-5 & 28 & 200 & 215 & 1.61 & 575 & 2.20 & 20.09 & 30.40 & 18.73 & 53.51 \\
\hline & B4-6 & 28 & 200 & 215 & 1.61 & 575 & 2.20 & 21.06 & 31.24 & 16.10 & 46.00 \\
\hline & B5-1 & 28 & 200 & 265 & 1.22 & 575 & 1.68 & 9.10 & 10.28 & 31.15 & 89.00 \\
\hline & B5-2 & 28 & 200 & 265 & 1.22 & 575 & 1.68 & 9.53 & 10.71 & 38.15 & 109.00 \\
\hline & B5-3 & 28 & 200 & 265 & 1.22 & 575 & 1.68 & 9.53 & 10.71 & 29.75 & 85.00 \\
\hline & B5-4 & 28 & 200 & 265 & 1.22 & 575 & 1.68 & 5.76 & 6.99 & 40.95 & 117.00 \\
\hline & B5-5 & 28 & 200 & 265 & 1.22 & 575 & 1.68 & 14.18 & 19.42 & 25.55 & 73.00 \\
\hline & B5-6 & 28 & 200 & 265 & 1.22 & 575 & 1.68 & 17.80 & 22.81 & 25.20 & 72.00 \\
\hline & B6-1 & 28 & 200 & 315 & 0.99 & 575 & 1.36 & 5.67 & 6.90 & 58.98 & 168.51 \\
\hline & B6-2 & 28 & 200 & 315 & 0.99 & 575 & 1.36 & 1.39 & 2.67 & 65.98 & 188.51 \\
\hline & B6-3 & 28 & 200 & 315 & 0.99 & 575 & 1.36 & 4.69 & 5.93 & 57.40 & 164.00 \\
\hline & B6-4 & 28 & 200 & 315 & 0.99 & 575 & 1.36 & 10.08 & 15.57 & 36.93 & 105.51 \\
\hline & B6-5 & 28 & 200 & 315 & 0.99 & 575 & 1.36 & 3.37 & 4.63 & 48.48 & 138.51 \\
\hline & B6-6 & $28\left(f_{\mathrm{cyl}, 75}\right)$ & 200 & 315 & 0.99 & 575 & 1.36 & 20.02 & 30.34 & 35.00 & 100.00 \\
\hline
\end{tabular}


(Continued)

\begin{tabular}{|c|c|c|c|c|c|c|c|c|c|c|c|}
\hline \multirow{2}{*}{ literature } & \multirow{2}{*}{ specimen } & \multirow[b]{2}{*}{$\begin{array}{c}\text { concrete } \\
\text { strength } \\
(\mathrm{MPa})\end{array}$} & \multirow[b]{2}{*}{$\begin{array}{c}b \\
(\mathrm{~mm})\end{array}$} & \multirow[b]{2}{*}{$\begin{array}{c}h \\
(\mathrm{~mm})\end{array}$} & \multirow[b]{2}{*}{$\begin{array}{c}\rho_{1} \\
(\%)\end{array}$} & \multirow[b]{2}{*}{$\begin{array}{c}\varepsilon_{\mathrm{y}} \\
(\mathrm{MPa})\end{array}$} & \multirow[b]{2}{*}{$\lambda$} & \multirow[b]{2}{*}{$\begin{array}{l}\eta_{\mathrm{wt}} \\
(\%)\end{array}$} & \multirow[b]{2}{*}{$\begin{array}{c}\eta_{\mathrm{sn}} \\
(\%)\end{array}$} & \\
\hline & & & & & & & & & & $\begin{array}{l}M_{\mathrm{fx}, \exp } \\
(\mathrm{kN} \cdot \mathrm{m})\end{array}$ & $\begin{array}{c}P_{\mathrm{fx}, \exp } \\
(\mathrm{kN})\end{array}$ \\
\hline \multirow{24}{*}{$\begin{array}{l}\text { Azad et al. } \\
{[25]} \\
(24 \text { tests })\end{array}$} & BT1-2-4 & 38.91 & 150 & 150 & 0.92 & 520 & 3.10 & 5.40 & 6.63 & 10.68 & 30.51 \\
\hline & BT1-3-4 & 36.89 & 150 & 150 & 0.92 & 520 & 3.10 & 14.20 & 19.43 & 10.15 & 29.00 \\
\hline & BT1-2-6 & 45.77 & 150 & 150 & 0.92 & 520 & 3.10 & 15.20 & 20.37 & 10.46 & 29.89 \\
\hline & BT1-3-6 & 46.45 & 150 & 150 & 0.92 & 520 & 3.10 & 21.40 & 31.54 & 9.15 & 26.14 \\
\hline & BT1-2-8 & 33.40 & 150 & 150 & 0.92 & 520 & 3.10 & 21.50 & 31.63 & 7.82 & 22.34 \\
\hline & BT1-3-8 & 46.45 & 150 & 150 & 0.92 & 520 & 3.10 & 31.00 & 44.73 & 6.48 & 18.51 \\
\hline & BT2-2-4 & 39.94 & 150 & 150 & 1.33 & 590 & 3.10 & 5.50 & 6.73 & 12.76 & 36.46 \\
\hline & BT2-3-4 & 35.68 & 150 & 150 & 1.33 & 590 & 3.10 & 8.80 & 9.99 & 11.97 & 34.20 \\
\hline & BT2-2-6 & 44.45 & 150 & 150 & 1.33 & 590 & 3.10 & 21.10 & 31.28 & 10.43 & 29.80 \\
\hline & ВT2-3-6 & 44.21 & 150 & 150 & 1.33 & 590 & 3.10 & 14.00 & 19.25 & 10.55 & 30.14 \\
\hline & BT2-2-8 & 44.69 & 150 & 150 & 1.33 & 590 & 3.10 & 22.90 & 32.85 & 8.88 & 25.37 \\
\hline & BT2-3-8 & 37.66 & 150 & 150 & 1.33 & 590 & 3.10 & 25.50 & 35.11 & 8.49 & 24.26 \\
\hline & ВT3-2-4 & 40.18 & 150 & 150 & 1.06 & 520 & 3.54 & 8.00 & 9.20 & 10.92 & 31.20 \\
\hline & ВT3-3-4 & 35.68 & 150 & 150 & 1.06 & 520 & 3.54 & 9.10 & 10.28 & 10.19 & 29.11 \\
\hline & ВT3-2-6 & 33.40 & 150 & 150 & 1.06 & 520 & 3.54 & 10.10 & 15.58 & 9.88 & 28.23 \\
\hline & ВT3-3-6 & 44.21 & 150 & 150 & 1.06 & 520 & 3.54 & 17.60 & 22.63 & 9.28 & 26.51 \\
\hline & ВT3-2-8 & 33.40 & 150 & 150 & 1.06 & 520 & 3.54 & 21.40 & 31.54 & 9.12 & 26.06 \\
\hline & ВT3-3-8 & 33.40 & 150 & 150 & 1.06 & 520 & 3.54 & 34.80 & 47.77 & 6.60 & 18.86 \\
\hline & BT4-2-4 & 36.89 & 150 & 150 & 1.54 & 590 & 3.57 & 7.90 & 9.10 & 12.03 & 34.37 \\
\hline & BT4-3-4 & 46.49 & 150 & 150 & 1.54 & 590 & 3.57 & 10.90 & 16.34 & 10.93 & 31.23 \\
\hline & BT4-2-6 & 46.49 & 150 & 150 & 1.54 & 590 & 3.57 & 13.40 & 18.68 & 10.02 & 28.63 \\
\hline & BT4-3-6 & 40.94 & 150 & 150 & 1.54 & 590 & 3.57 & 18.60 & 23.57 & 8.98 & 25.66 \\
\hline & BT4-2-8 & 40.94 & 150 & 150 & 1.54 & 590 & 3.57 & 18.00 & 23.00 & 9.00 & 25.71 \\
\hline & BT4-3-8 & $37.66\left(f_{\mathrm{cyl}, 75}\right)$ & 150 & 150 & 1.54 & 590 & 3.57 & 20.70 & 30.93 & 7.57 & 21.63 \\
\hline \multirow{8}{*}{$\begin{array}{l}\text { Shang [36] } \\
\text { (8 tests) }\end{array}$} & L10 & 42.78 & 151 & 200 & 1.61 & 321 & 3.64 & 0.00 & 0.00 & 21.37 & 35.62 \\
\hline & L11 & 42.78 & 150 & 200 & 1.61 & 321 & 3.59 & 7.21 & 8.42 & 17.82 & 29.70 \\
\hline & L12 & 42.78 & 150 & 200 & 1.61 & 321 & 3.61 & 9.63 & 10.80 & 17.51 & 29.18 \\
\hline & L13 & 42.78 & 152 & 200 & 1.61 & 321 & 3.57 & 16.23 & 21.34 & 14.98 & 24.97 \\
\hline & L20 & 44.90 & 151 & 200 & 0.89 & 313 & 3.57 & 0.00 & 0.00 & 11.21 & 18.68 \\
\hline & L21 & 44.90 & 151 & 200 & 0.89 & 313 & 3.53 & 6.47 & 7.69 & 11.53 & 19.22 \\
\hline & L22 & 44.90 & 150 & 200 & 0.89 & 313 & 3.59 & 12.42 & 13.56 & 11.26 & 18.77 \\
\hline & L23 & $\begin{array}{c}44.90 \\
\left(f_{\mathrm{cu}, 150}\right)\end{array}$ & 151 & 200 & 0.89 & 313 & 3.55 & 19.32 & 29.73 & 9.21 & 15.35 \\
\hline
\end{tabular}




\begin{tabular}{|c|c|c|c|c|c|c|c|c|c|c|c|}
\hline \multirow[b]{2}{*}{ literature } & \multirow[b]{2}{*}{ specimen } & \multirow[b]{2}{*}{$\begin{array}{c}\text { concrete } \\
\text { strength } \\
(\mathrm{MPa})\end{array}$} & \multirow[b]{2}{*}{$\begin{array}{c}b \\
(\mathrm{~mm})\end{array}$} & \multirow[b]{2}{*}{$\begin{array}{c}h \\
(\mathrm{~mm})\end{array}$} & \multirow[b]{2}{*}{$\begin{array}{c}\rho_{1} \\
(\%)\end{array}$} & \multirow[b]{2}{*}{$\begin{array}{c}\varepsilon_{\mathrm{y}} \\
(\mathrm{MPa})\end{array}$} & \multirow[b]{2}{*}{$\lambda$} & \multirow[b]{2}{*}{$\begin{array}{l}\eta_{\mathrm{wt}} \\
(\%)\end{array}$} & \multirow[b]{2}{*}{$\begin{array}{l}\eta_{\mathrm{sn}} \\
(\%)\end{array}$} & \multicolumn{2}{|c|}{ (Continued) } \\
\hline & & & & & & & & & & $\begin{array}{c}M_{\mathrm{fx}, \exp } \\
(\mathrm{kN} \cdot \mathrm{m})\end{array}$ & $\begin{array}{c}P_{\mathrm{fx}, \exp } \\
(\mathrm{kN})\end{array}$ \\
\hline \multirow{16}{*}{$\begin{array}{l}\text { Rodriguez } \\
\text { et al. [4] } \\
\text { (16 tests) }\end{array}$} & 1 & 52.60 & 150 & 200 & 0.92 & 585 & 4.88 & 11.81 & 17.19 & 17.8 & 22.25 \\
\hline & 111 & 62.62 & 150 & 200 & 0.63 & 575 & 4.85 & 0.00 & 0.00 & 15.1 & 18.88 \\
\hline & 112 & 62.62 & 150 & 200 & 0.63 & 575 & 4.85 & 0.00 & 0.00 & 15.7 & 19.63 \\
\hline & 115 & 42.58 & 150 & 200 & 0.63 & 575 & 4.85 & 8.29 & 13.88 & 11.6 & 14.50 \\
\hline & 114 & 42.58 & 150 & 200 & 0.63 & 575 & 4.85 & 11.81 & 17.19 & 10.5 & 13.13 \\
\hline & 113 & 42.58 & 150 & 200 & 0.63 & 575 & 4.85 & 13.35 & 18.64 & 10.1 & 12.63 \\
\hline & 121 & 60.11 & 150 & 200 & 1.84 & 585 & 4.88 & 0.00 & 0.00 & 36.1 & 45.13 \\
\hline & 122 & 60.11 & 150 & 200 & 1.84 & 585 & 4.88 & 0.00 & 0.00 & 38.3 & 47.88 \\
\hline & 126 & 43.82 & 150 & 200 & 1.84 & 585 & 4.88 & 9.2 & 10.38 & 29 & 36.25 \\
\hline & 211 & 62.62 & 150 & 200 & 1.84 & 585 & 4.88 & 0.00 & 0.00 & 38.4 & 48.00 \\
\hline & 212 & 62.62 & 150 & 200 & 1.84 & 585 & 4.88 & 0.00 & 0.00 & 39.4 & 49.25 \\
\hline & 311 & 61.36 & 150 & 200 & 1.84 & 585 & 4.88 & 0.00 & 0.00 & 38.1 & 47.63 \\
\hline & 312 & 61.36 & 150 & 200 & 1.84 & 585 & 4.88 & 0.00 & 0.00 & 38.8 & 48.50 \\
\hline & 313 & 46.34 & 150 & 200 & 1.84 & 585 & 4.88 & 8.56 & 9.75 & 28.2 & 35.25 \\
\hline & 314 & 46.34 & 150 & 200 & 1.84 & 585 & 4.88 & 9.86 & 15.36 & 28.5 & 35.63 \\
\hline & 316 & $\begin{array}{c}46.34 \\
\left(f_{\mathrm{cyl}, 150}\right)\end{array}$ & 150 & 200 & 1.84 & 585 & 4.88 & 7.89 & 13.51 & 27.5 & 34.38 \\
\hline \multirow{7}{*}{$\begin{array}{l}\text { Chen [37] } \\
\text { (7 tests) }\end{array}$} & 1 & 30 & 120 & 200 & 0.83 & 335 & 2.55 & 0.00 & 0.00 & 7.88 & 19.70 \\
\hline & 2 & 30 & 120 & 200 & 0.83 & 335 & 2.55 & 0.5 & 1.79 & 8.82 & 22.05 \\
\hline & 3 & 30 & 120 & 200 & 0.83 & 335 & 2.55 & 1 & 2.29 & 8.02 & 20.05 \\
\hline & 4 & 30 & 120 & 200 & 0.83 & 335 & 2.55 & 3 & 4.26 & 7.23 & 18.08 \\
\hline & 5 & 30 & 120 & 200 & 0.83 & 335 & 2.55 & 6 & 7.22 & 5.78 & 14.45 \\
\hline & 6 & 30 & 120 & 200 & 0.83 & 335 & 2.55 & 12 & 17.37 & 5.11 & 12.78 \\
\hline & 7 & $30\left(f_{\mathrm{cu}, 150}\right)$ & 120 & 200 & 0.83 & 335 & 2.55 & 24 & 33.80 & 2.84 & 7.10 \\
\hline \multirow{13}{*}{$\begin{array}{l}\text { Zhang [38] } \\
\text { (13 tests) }\end{array}$} & 1 & 23.56 & 120 & 180 & 0.87 & 335 & 3.44 & 0.00 & 0.00 & 6.40 & 12.30 \\
\hline & 2 & 23.56 & 120 & 180 & 0.87 & 335 & 3.44 & 0.00 & 0.00 & 6.84 & 13.15 \\
\hline & 3 & 23.56 & 120 & 180 & 0.87 & 335 & 3.44 & 0.00 & 0.00 & 6.68 & 12.85 \\
\hline & 4 & 23.56 & 120 & 180 & 0.87 & 335 & 3.44 & 0.00 & 0.00 & 6.55 & 12.60 \\
\hline & 5 & 23.56 & 120 & 180 & 0.87 & 335 & 3.44 & 1.23 & 2.51 & 6.97 & 13.40 \\
\hline & 6 & 23.56 & 120 & 180 & 0.87 & 335 & 3.44 & 1.77 & 3.05 & 7.05 & 13.55 \\
\hline & 7 & 23.56 & 120 & 180 & 0.87 & 335 & 3.44 & 2.43 & 3.70 & 7.10 & 13.65 \\
\hline & 8 & 23.56 & 120 & 180 & 0.87 & 335 & 3.44 & 2.92 & 4.18 & 6.99 & 13.45 \\
\hline & 9 & 23.56 & 120 & 180 & 0.87 & 335 & 3.44 & 3.57 & 4.82 & 6.08 & 11.70 \\
\hline & 10 & 23.56 & 120 & 180 & 0.87 & 335 & 3.44 & 5.08 & 6.31 & 6.44 & 12.39 \\
\hline & 11 & 23.56 & 120 & 180 & 0.87 & 335 & 3.44 & 5.94 & 7.16 & 6.34 & 12.20 \\
\hline & 12 & 23.56 & 120 & 180 & 0.87 & 335 & 3.44 & 6.72 & 7.93 & 6.47 & 12.45 \\
\hline & 13 & $23.56\left(f_{\mathrm{cu}, 150}\right)$ & 120 & 180 & 0.87 & 335 & 3.44 & 6.91 & 8.12 & 6.53 & 12.55 \\
\hline
\end{tabular}


strength of concrete is required. As shown in Table 1, different researchers defined the compressive strength of concrete by using different testing standards. For comparative analysis, different concrete strengths require uniform standards [40]. Eurocode 2 [41] proposed the conversion relationship among $f_{\text {cyl }, 150}, f_{\mathrm{t}}$ (concrete axis tensile strength) and $f_{\mathrm{cu}, 150}$, which can be observed from Table 2. GB50010-2002 [33] gives the conversion relationship between $f_{\text {ck }}$ (concrete prism compressive strength with specimens of $150 \mathrm{~mm} \times 150 \mathrm{~mm} \times$ $300 \mathrm{~mm}$ ) and $f_{\mathrm{cu}, 150}$, which is also listed in Table 2 . According to Refs. [42,43], $f_{\text {cyl }, 150}=0.96 f_{\text {cyl }, 75}$ is adopted in this study.

2.3 Conversion relations between the section loss ratio and the weight loss ratio

Different researchers characterized the corrosion degree of the steel bars by using different methods in the published literature, such as the section loss ratio $\left(\eta_{\mathrm{sn}}\right)$ and the weight loss ratio $\left(\eta_{\mathrm{wt}}\right)$ presented in Table 1 . The calculation of $\eta_{\mathrm{wt}}$ and $\eta_{\mathrm{sn}}$ can be expressed as Eqs. (1) and (2), respectively:

$$
\begin{aligned}
\eta_{\mathrm{wt}} & =\left(m_{0}-m\right) / m_{0} \times 100 \%, \\
\eta_{\mathrm{sn}} & =\left(A_{0}-A_{\min }\right) / A_{0} \times 100 \% \\
& =\left(d_{0}^{2}-d_{\min }^{2}\right) / d_{0}^{2} \times 100 \%,
\end{aligned}
$$

where $m_{0}, A_{0}$, and $d_{0}$ are the initial mass, cross-sectional area, and diameter of the steel reinforcement, respectively; $m$ corresponds to the remaining mass of the steel reinforcement after corrosion; and $A_{\min }$ and $d_{\min }$ are the minimum remaining cross-sectional area and diameter of the steel reinforcement after corrosion, respectively.

For comparative analysis, different corrosion degree requires uniform standards. According to the experimental investigation [44], the conversion relationship between $\eta_{\mathrm{wt}}$ and $\eta_{\mathrm{s} n}$ can be obtained by:

$$
\eta_{\mathrm{sn}}= \begin{cases}0.013+0.987 \eta_{\mathrm{wt}}, & \eta_{\mathrm{wt}}<10 \%, \\ 0.061+0.939 \eta_{\mathrm{wt}}, & 10 \% \leqslant \eta_{\mathrm{wt}}<20 \%, \\ 0.129+0.871 \eta_{\mathrm{wt}}, & 20 \% \leqslant \eta_{\mathrm{wt}}<30 \%, \\ 0.199+0.801 \eta_{\mathrm{wt}}, & 30 \% \leqslant \eta_{\mathrm{wt}} \leqslant 40 \% .\end{cases}
$$

\section{Influencing parameters on residual flexural strength of CRC beam}

Using the experimental database established, this section compared and analyzed the influence of some important parameters on the residual flexural strength of CRC beams. The main parameters include the width of beam section (b), the effective height of beam section $\left(h_{0}\right)$, the concrete cylinder compressive strength with specimens of $150 \mathrm{~mm}$ $\times 300 \mathrm{~mm}\left(f_{\text {cyl,150 }}\right)$, and the weight loss ratio of the longitudinal reinforcement $\left(\eta_{\mathrm{wt}}\right)$. Taking the influence of the cross-sectional dimensions of the experimental beam members and the strength of the concrete into account, this section defined the ultimate flexural stress of CRC beams as $\sigma_{\mathrm{fx}, \exp }=P_{\mathrm{fx}, \exp } / b h_{0}$ and normalized ultimate flexural stress as $\sigma_{\mathrm{fxn}, \exp }=M_{\mathrm{fx}, \exp } / f_{\text {cyl } 150}$. The calculation method for the effective height of the test beam $\left(h_{0}\right)$ [33] can be expressed as:

$$
h_{0}=h-a_{\mathrm{s}},
$$

where $a_{\mathrm{s}}$ denotes the distance from the point of application of the longitudinal reinforcement to the tensioned edge of the beam section. This section draws graphs of the relationship between various the ultimate flexural stress, the normalized ultimate flexural stress of CRC beams $\left(\sigma_{\mathrm{fx}, \exp }\right.$ and $\left.\sigma_{\mathrm{fxn}, \exp }\right)$ and parameters, respectively.

\subsection{Longitudinal reinforcement corrosion ratio}

The ultimate flexural stress of CRC beams $\left(\sigma_{\mathrm{fx}, \exp }\right)$ varied with the corrosion ratio of the longitudinal reinforcement (represented by the weight loss ratio $\eta_{\mathrm{wt}}$ ) and the trend lines obtained using regression analysis are illustrated in Fig. 1, where the three trend lines represent the experimental results of Xia et al. [35], Azad et al. [25], and Chen [37], respectively. From the Fig. 1, it can be seen that the defined ultimate flexural stress of test beams as a whole decreases with the increase of the longitudinal reinforcement corrosion ratio. When the corrosion ratio of the longitudinal reinforcement $\eta_{\mathrm{wt}}$ is not larger than $10 \%$, the downward trend is not obvious. However, when the corrosion ratio of the longitudinal reinforcement $\eta_{\mathrm{wt}}$ is larger than $10 \%$, the downward trend is obvious. Figure 1 also displays their corresponding coefficients of determination $\mathrm{R}^{2}$ of Xia et al. [35], Azad et al. [25], and Chen [37],

Table 2 The conversion relationship among $f_{\mathrm{cyl}, 150}, f_{\mathrm{t}}, f_{\mathrm{cu}, 150}$ and $f_{\mathrm{ck}}[41,33]$

\begin{tabular}{lccccccccccccccc}
\hline different strength of concrete & \multicolumn{10}{c}{ strength values $(\mathrm{MPa})$} \\
\hline$f_{\text {cyl, } 150}$ & 12 & 16 & 20 & 25 & 30 & 35 & 40 & 45 & 50 & 55 & 60 & 70 & 80 & 90 \\
$f_{\mathrm{t}}$ & 1.6 & 1.9 & 2.2 & 2.6 & 2.9 & 3.2 & 3.5 & 3.8 & 4.1 & 4.2 & 4.4 & 4.6 & 4.8 & 5.0 \\
$f_{\text {cu, } 150}$ & 15 & 20 & 25 & 30 & 37 & 45 & 50 & 55 & 60 & 67 & 75 & 85 & 95 & 105 \\
$f_{\text {ck }}$ & 10.0 & 13.4 & 16.7 & 20.1 & 24.8 & 30.2 & 33.5 & 36.9 & 40.2 & 44.9 & 50.3 & 56.9 & 63.4 & 70.4 \\
\hline
\end{tabular}


with the minimum value 0.106 of Xia et al. [35] and the maximum value 0.959 of Chen [37].

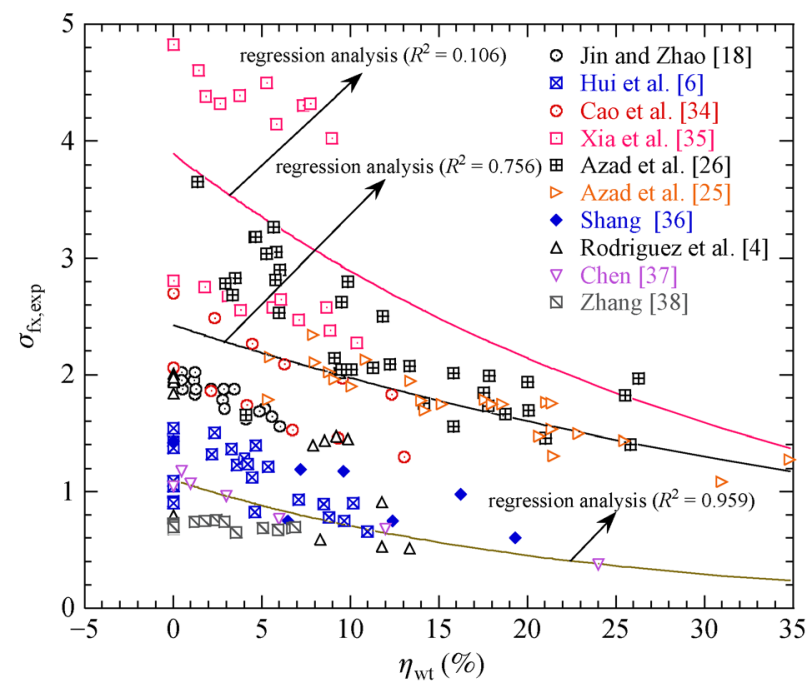

Fig. 1 Ultimate flexural stress $\left(\sigma_{\mathrm{fx}, \mathrm{exp}}\right)$ with respect to the corrosion ratio of longitudinal reinforcement $\left(\eta_{\mathrm{wt}}\right)$.

\subsection{Width and effective depth of beam section}

Figures 2 and 3 show the relationship between the beam width $b$, the effective height of the test beams $\left(h_{0}\right)$, and the ultimate flexural stress $\left(\sigma_{\mathrm{fx}, \exp }\right)$ of CRC beams, respectively, in which the trend lines are also obtained from regression analysis. To simultaneously consider the influence of the weight loss ratio of the longitudinal reinforcement, all experimental data are divided into four groups according to the value of $\eta_{\mathrm{wt}}$, i.e., $\eta_{\mathrm{wt}}<10 \%$, $10 \% \leqslant \eta_{\mathrm{wt}}<20 \%, 20 \% \leqslant \eta_{\mathrm{wt}}<30 \%$, and $\eta_{\mathrm{wt}} \geqslant 30 \%$. As observed from Figs. 2 and 3, the ultimate flexural stress of CRC beams has a tendency to increase gradually when $b$ and $h_{0}$ are increasing, while the increasing trend is not obvious with low value of $R^{2}$, the value of which are 0.094 and 0.010 , respectively. This shows that the cross-section parameters of the test beams ( $b$ and $h_{0}$ ) are less correlated with the ultimate flexural stress of CRC beams.

\subsection{Compressive strength of cylindrical concrete}

The normalized ultimate flexural stress $\left(\sigma_{\mathrm{fxn}, \exp }\right)$ varied with the concrete strength, represented by the concrete cylinder compressive strength $\left(f_{\text {cyl } 1,150}\right)$, is illustrated in Fig. 4. Regression analysis also gives the trend lines in Fig. 4, which includes the lines that the range of the weight loss ratio of the longitudinal reinforcement are $10 \% \leqslant$ $\eta_{\mathrm{wt}}<20 \%$, and $\eta_{\mathrm{wt}}<10 \%$, respectively. As can be observed from the Fig. 4 that the defined normalized ultimate flexural stress of the test beams as a whole decreases with the increase of the concrete cylinder compressive strength $\left(f_{\text {cyl, } 150}\right)$. When the corrosion ratio

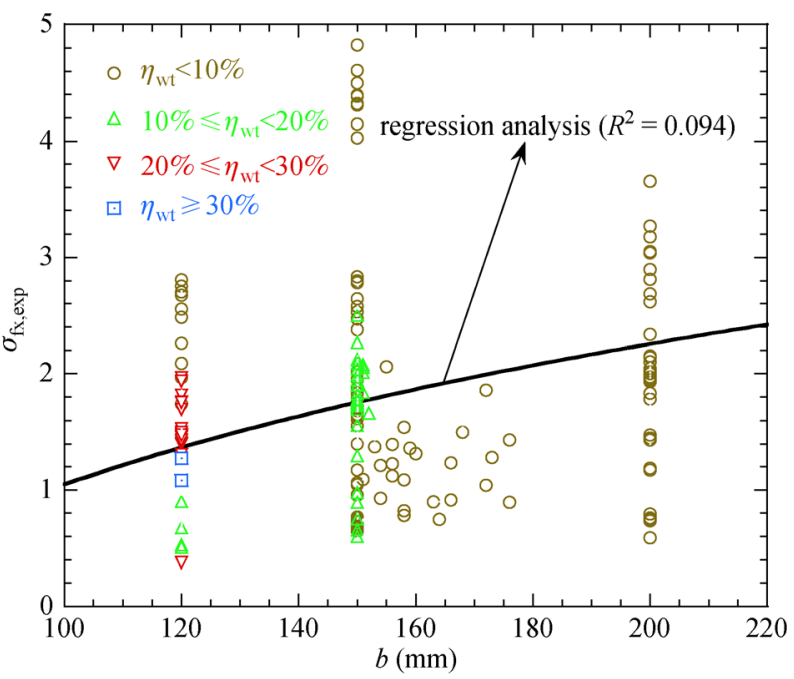

Fig. 2 Ultimate flexural stress $\left(\sigma_{\mathrm{fx}, \exp }\right)$ with respect to width of beam section $(b)$.

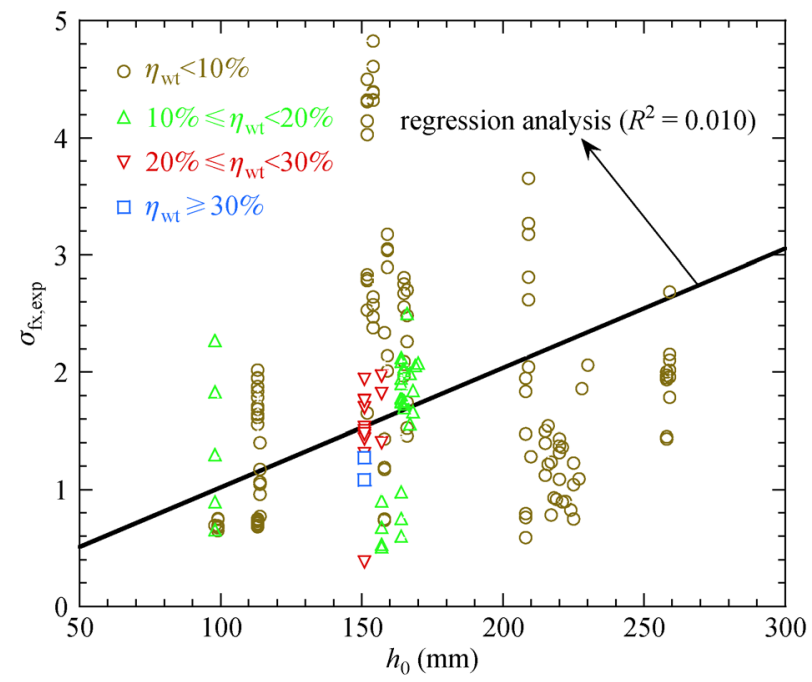

Fig. 3 Ultimate flexural stress $\left(\sigma_{\mathrm{fx}, \mathrm{exp}}\right)$ with respect to effective depth of beam section $\left(h_{0}\right)$.

of the longitudinal reinforcement varies between $10 \%$ and $20 \%$, the downward trend is more obvious, in which the value of $R^{2}$ is 0.507 . When the corrosion ratio of the longitudinal reinforcement is different, the correlation between the concrete cylinder compressive strength of the test beams and its normalized ultimate flexural stress is different as well.

3.4 Ratio of strength between longitudinal reinforcement and concrete

Figure 5 shows the relationship between the defined normalized ultimate flexural stress $\left(\sigma_{\mathrm{fxn}, \mathrm{exp}}\right)$ and the ratio of strength between longitudinal reinforcement and concrete, which is defined as $\rho_{1} f_{\mathrm{y}} / f_{\text {cyl } 150}$, in which $f_{\mathrm{y}}$ is 


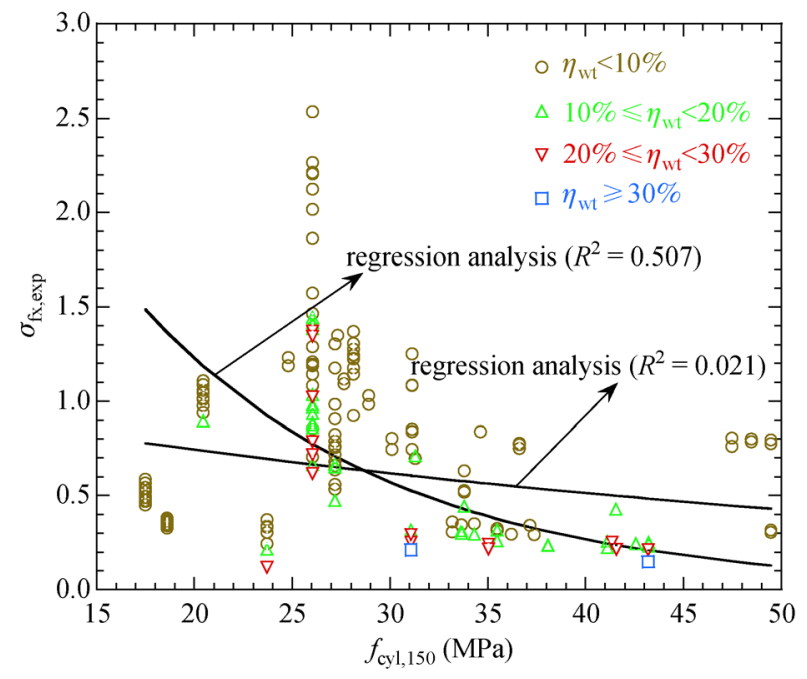

Fig. 4 Normalized ultimate flexural stress $\left(\sigma_{\text {fxn,exp }}\right)$ with respect to cylinder compressive strength of concrete $\left(f_{\text {cyl, } 150}\right)$.

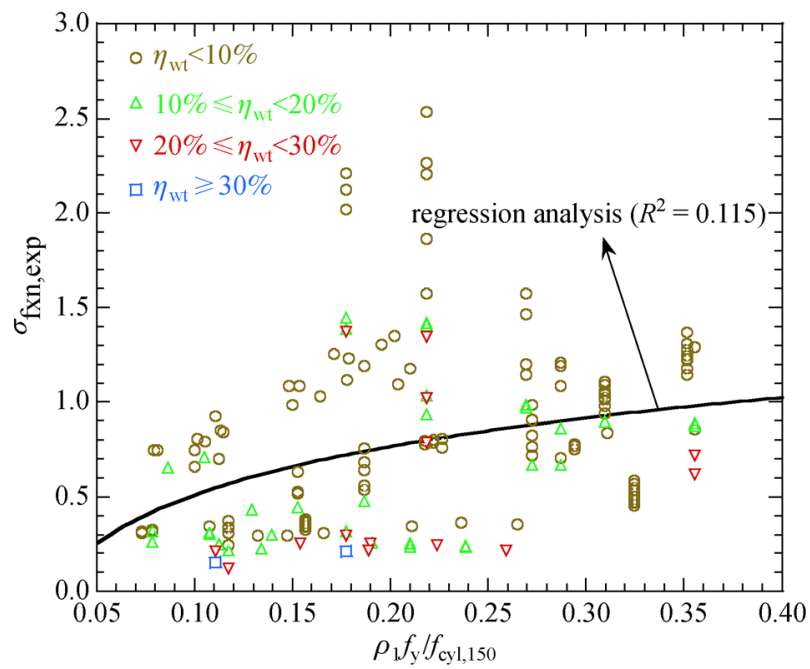

Fig. 5 Ultimate flexural stress $\left(\sigma_{\mathrm{fx}, \text { exp }}\right)$ with respect to ratio of strength between longitudinal reinforcement and concrete $\left(\rho_{1} f_{\mathrm{y}} / f_{\text {cyl }, 150}\right)$.

the yield strength of longitudinal reinforcements and $\rho_{1}$ is the section ratio between longitudinal reinforcements and concrete, together with their regression line. It can be observed from Fig. 5 that the defined normalized ultimate flexural stress of the test beams $\sigma_{\mathrm{fxn} \text {,exp }}$ increases with the increase of the ratio of strength between longitudinal reinforcement and concrete $\left(\rho_{1} f_{\mathrm{y}} / f_{\text {cyl,150}}\right)$, which demonstrates that the flexural strength of CRC beams will also increase within a reasonable range with the increasing of normalized strength of longitudinal reinforcement.

\section{Empirical models for predicting residual flexural strength of CRC beam}

In this part, six existing empirical models are selected for the predictions of the residual flexural capacity of CRC beams [22-27]. A brief introduction for the calculation process of each model is given as follows.

\subsection{Zhang et al.'s model [22]}

The calculation model of Zhang et al. [22] considered that the deformation coordination between longitudinal reinforcement and concrete after corrosion was no longer established, which means that the plane section assumption is no longer valid after corrosion. This model defined the relationship of strain between the concrete and the steel bar under the action of the ultimate bending moment. The experimental data were used to obtain the result of strain relationship between the concrete and steel bars, in which the steel bar included the deformed steel bar and the plain bar. The corrosion effect on the yield strength of longitudinal reinforcements was considered. The calculation formula for the height of the concrete compression zone of the beam with different corrosion ratios under the ultimate bending moment was given. Considering the influence of corrosion, the test beams were divided into two types of failure modes. According to different types of failure modes, the formula for calculating the flexural capacity of the beam with different failure modes was obtained.

\subsection{Xu's model [23]}

The combination of finite element analysis and experimental data was one of the characteristics of Xu's model [23]. Xu [23] pointed out that steel corrosion would cause the bond performance between concrete and steel bars to degrade, and the strain coordination relationship between them would change. It was first proposed that the strain relationship between steel and concrete after corrosion was no longer satisfied with the plain section assumption. Through the analysis of finite element and experimental study, the relationship of the strain ratio between concrete and steel bar under the action of ultimate bending strength was defined. The criterion for the ultimate flexural capacity of the test beam is that the maximum compressive strain of the concrete at the edge of the compression zone reaches the ultimate compressive strain. Based on the bending experiment and nonlinear finite element analysis of test beams, the calculation model of the residual flexural capacity of CRC beams is established by using the modified limit equilibrium theory. 


\subsection{Sun's model [24]}

This model first studied and analyzed the beam members with perfect bond and the unbonded beam members. Based on this, the causes and mechanisms of the reduction of RC beams' flexural capacity caused by corrosion were analyzed. This model defined the concept of section reinforcement index and reinforcement strength utilization coefficient of unbonded beam members, and simulated the relationship between section reinforcement index and reinforcement strength utilization coefficient through finite element analysis. On this basis, considering the influence of corrosion, this model defined the section reinforcement index of the corroded beams. The linear interpolation method was used to construct the relationship between the section reinforcement index and the reinforcement coefficient of CRC beams in the two extreme states of the perfect bonded and unbonded situation. Ultimately, the flexural strength of CRC beams was calculated according to the reinforcement coefficient.

\subsection{Azad et al.'s model [25]}

As for Azad et al.'s model [25], the corrosion activity index was considered to be the most critical factor which affects the flexural capacity of CRC beams according to this model's experiment. This model calculated the ultimate flexural strength of CRC beam members in two steps. In the first step, only the influence of corrosion on the section of the steel bar was considered, and the ultimate flexural capacity of the corroded reinforced concrete beam members was calculated according to the existing specifications; and in the second step, the effect of corrosion on the bond strength between concrete and steel was taken into account, and a collaborative work coefficient was fitted through the experiment and multiplied by the result calculated in the first step to obtain the final calculation result.

\subsection{Azad et al.'s modified model [26]}

This model was a new modified model of Azad et al. [26] by considering the size effect of the test beam section. The modified model [26] was consistent with the previously proposed model calculation, and was also divided into two steps. The difference was that the new modified model took the influence of the cross-section dimensions of the test beam into account and three sets of test beams with different cross-section dimensions were produced. A new collaborative work coefficient considering the influence of the cross-section dimensions was proposed.

\subsection{Torres-Acosta et al.'s model [27]}

The model indicated that the maximum pitting corrosion depth of longitudinal reinforcement caused by corrosion was the most important parameter affecting the flexural capacity of CRC beams. Based on the regression analysis of the experimental results, this model gave the relationship between the average corrosion depth and the maximum corrosion depth. The relationship between the maximum corrosion depth of the corroded steel bar and the residual flexural strength of test beams was fitted.

\section{Comparison between test results and predictions of existing models}

Figures 6(a)-6(f) show the calculation results of 177 sets of experimental data in experimental database by each model [22-27]. The abscissa of the graph represents the weight loss ratio of the longitudinal reinforcement, and the ordinate represents the ratio between the test results of ultimate flexural capacity of the CRC beam members and the models' predicted values $\left(M_{\mathrm{fx}, \mathrm{exp}} / M_{\mathrm{fx}, \mathrm{cal}}\right)$. To conduct a comprehensive comparative analysis of each model, Table 3 lists the mean, standard deviation, maximum and minimum values, and the difference between the maximum and minimum values for each model of all 177 experimental data. From Figs. 6(a)-6(f) and Table 3, the following can be obtained.

1) From the calculation results of Zhang et al. [22], it can be observed that the ratios of 137 (about $77.4 \%$ of all) experimental specimens are more than 1.0 , indicating that the experimental value of the ultimate flexural moment is larger than the predicted value of the model, which shows that the calculation result of this model is conservative. It can also be seen from Fig. 6(a) that when the weight loss ratio of the steel $\left(\eta_{\mathrm{wt}}\right)$ is between 0 and $10 \%$, the calculation result is closer to 1.0 , which means that the prediction result is more accurate. When the weight loss ratio of the longitudinal reinforcement $\left(\eta_{\mathrm{wt}}\right)$ becomes large, the prediction error of this model will increase. This model has the average and standard deviation of the ratio with 1.118 and 0.246 for the 177 sets of data in the experimental database, respectively. The maximum value of the calculation result is 2.221 and the minimum value is 0.564 .

2) It can be observed from the model calculation results of $\mathrm{Xu}$ [23] that more than $87 \%$ of the ratios of $M_{\mathrm{fx}, \exp } / M_{\mathrm{fx}, \mathrm{cal}}$ are greater than 1.0 and only a small part of the calculation results are less than 1.0 indicating that the calculation result of this model is conservative. At the same time, a clear trend can be found from the Fig. 6(b) that as the weight loss ratio of the longitudinal reinforcement increasing, the calculation result will also increase. This means that the greater the corrosion rates of the longitudinal reinforcement, the larger the calculation error of this model and the more conservative of this model's calculation result. The mean value of the model calculation 


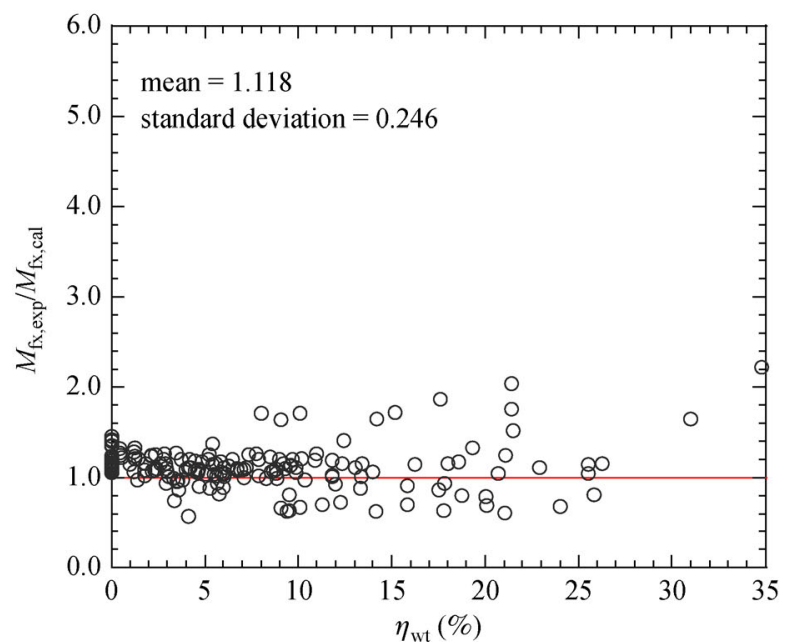

(a)

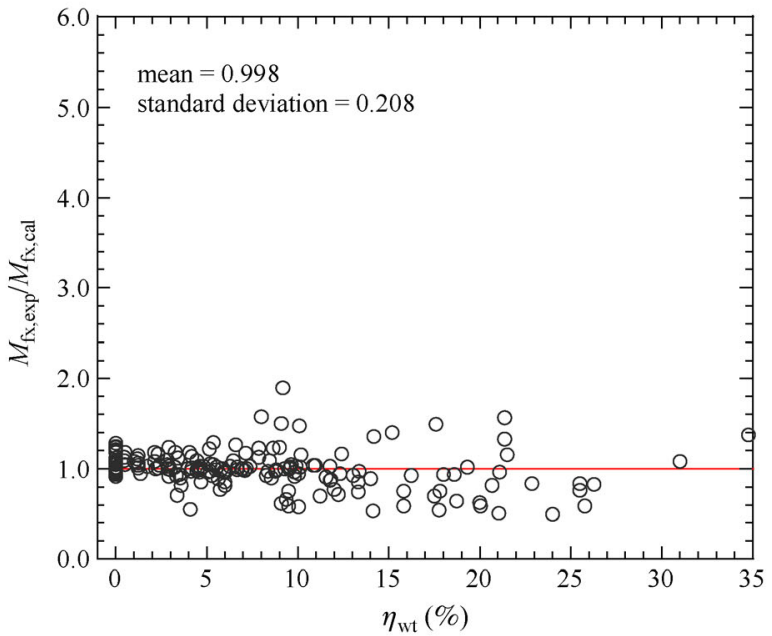

(c)

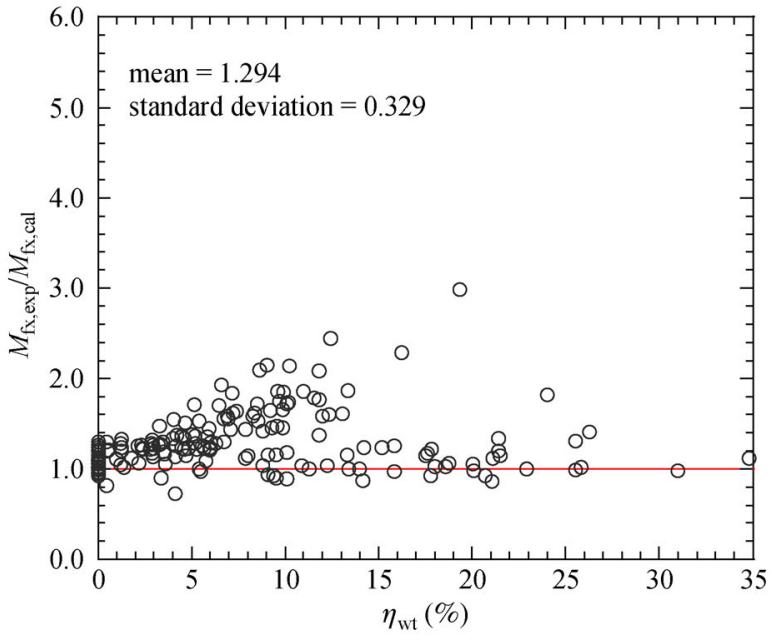

(e)

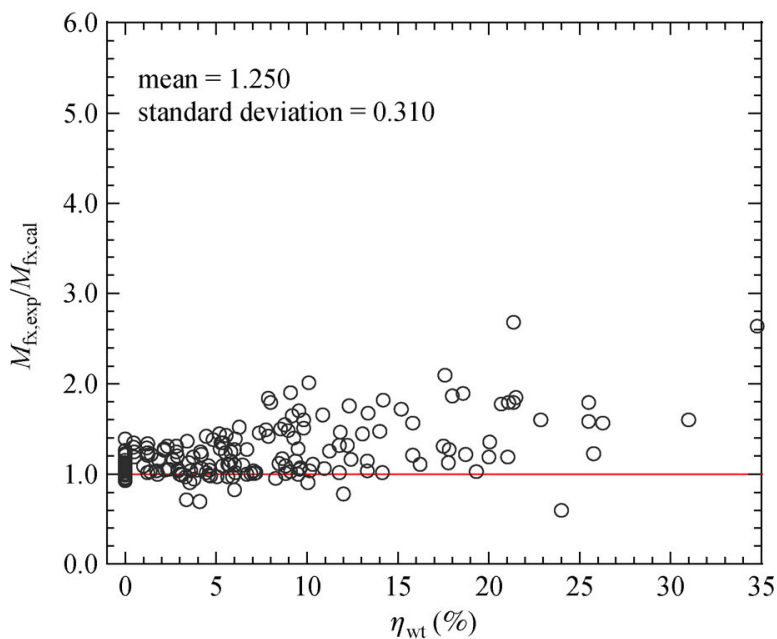

(b)

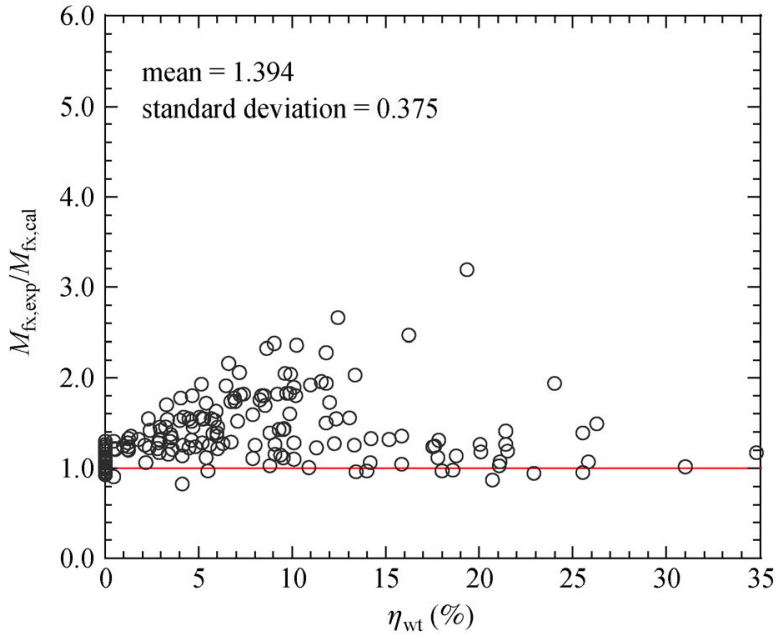

(d)

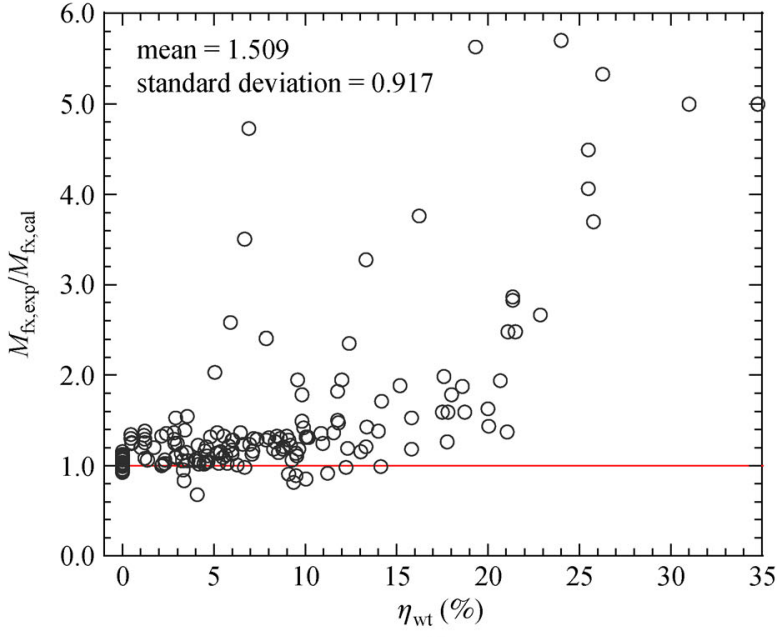

(f)

Fig. 6 The relations between the ratios $\left(M_{\mathrm{fx}, \exp } / M_{\mathrm{fx}, \mathrm{cal}}\right)$ and weight loss ratio of the longitudinal reinforcement $\left(\eta_{\mathrm{wt}}\right)$ of the existing models. (a) Zhang et al.'s model [22]; (b) Xu's model [23]; (c) Sun's model [24]; (d) Azad et al.'s model [25]; (e) Azad et al.'s modified model [26]; (f) Torres-Acosta et al.'s model [27]. 
Table 3 Comparisons on residual flexural capacity of CRC beams from tests and predictions of existing empirical models and the new proposal

\begin{tabular}{|c|c|c|c|c|c|}
\hline \multirow[t]{2}{*}{ literature } & \multicolumn{5}{|c|}{ the ratios of test results to the predictions of existing models and new model } \\
\hline & mean & standard deviation & maximum & minimum & maximum-minimum \\
\hline Zhang et al. [22] & 1.118 & 0.246 & 2.221 & 0.564 & 1.657 \\
\hline $\mathrm{Xu}[23]$ & 1.250 & 0.310 & 2.682 & 0.597 & 2.085 \\
\hline Sun $[24]$ & 0.998 & 0.208 & 1.895 & 0.497 & 1.398 \\
\hline Azad et al. [25] & 1.394 & 0.375 & 3.197 & 0.824 & 2.373 \\
\hline Azad et al. [26] & 1.294 & 0.329 & 2.979 & 0.722 & 2.257 \\
\hline Torres-Acosta et al. [27] & 1.509 & 0.917 & 5.501 & 0.683 & 4.818 \\
\hline The new proposal & 1.030 & 0.171 & 1.653 & 0.626 & 1.027 \\
\hline
\end{tabular}

is 1.250 , and the standard deviation is 0.310 . The maximum value of the calculation result is 2.682 and the minimum value is 0.597 .

3) Sun's [24] model has better calculation results among the existing empirical models. In the results of 177 sets of experimental data, the average value of the model is 0.998 and the standard deviation is 0.208 . Moreover, compared with other models $[23,27]$, the calculation results of Sun's model are more accurate when the weight loss ratio of longitudinal reinforcements is large. However, according to the experimental data of the model calculation results, it is found that nearly $50 \%$ of the data results are less than 1.0 . In other words, the model overestimates the ultimate flexural capacity of CRC beams and the calculation results may be unsafe for engineering applications.

4) It can be observed from the model calculation results of Azad et al. [25] that about $92 \%$ of the ratios of $M_{\mathrm{fx}, \exp } / M_{\mathrm{fx}, \mathrm{cal}}$ are greater than 1.0. The calculation results of this model are conservative and underestimate the ultimate flexural capacity of CRC beams. Additionally, when the test beam specimens come from the test beam members made by this model itself, the model's calculation results will be more accurate. But when the test beam specimens come from other literatures, the calculation error of this model is relatively large indicting that this model has poor universality when calculating the ultimate flexural moment of CRC beams with the mean and standard deviation of the ratios of 1.394 and 0.375 , respectively.

5) It can be observed from the calculation results that the modified model of Azad et al. [26] is better than the previous model of Azad et al. [25]. The mean of the calculated results was reduced to 1.294 and the standard deviation was reduced to 0.329 . However, the modified model still has the problems that the calculation results are conservative and the generality of the model calculation is poor with the values of maximum of 2.979 and the values of minimum of 0.722 , respectively.

6) As can be observed from the Fig. 6(f), more than $90 \%$ of the calculation results are greater than 1.0 in the TorresAcosta et al.'s model [27]. The calculation results of the model are conservative and underestimate the ultimate bending capacity of CRC beams. Figure 6(f) also shows that as the weight loss ratio of the steel increases, the calculation error increases continuously; and when the weight loss ratio of steel is greater than $20 \%$, the calculation result of the model is too high. The mean of this model's result is 1.509 , and the value of the standard deviation is 0.917 .

The experimental flexural capacity of CRC beam specimens in Table 1 corresponding with those predicted by the six empirical models [22-27] are illustrated in Figs. 7(a)-7(f), respectively. The mean square errors $(M S E)$ and coefficients of determination $\left(R^{2}\right)$ are also shown in Figs. 7(a)-7(f). The abscissa of the graphs represents the predicted flexural capacity, and the ordinate represents the experimental flexural capacity. From these figures we can observed that six collected models [22-27] generally give underestimated experimental results of Azad et al. [26] except for the model of Zhang et al. [22] and Sun [24] which generally overestimate test results of Azad et al. [26]. Overall, Azad et al.'s model [25] gives the values of $R^{2}$ around 0.65 and the values of MSE about 57, which are the worst predictions among these models. It can be observed that almost all the predicted flexural capacity is less than the experimental flexural capacity including themselves experimental data. Azad et al.'s modified model [26] improves the calculation accuracy $\left(R^{2} \approx 0.78\right.$, MSE $\approx 36$ ) but still have the aforementioned problem. Sun's model [24] gave worse predictions when calculating the experimental data from Azad et al. [26] with the values of $R^{2}$ around 0.75 and the values of MSE about 40. Zhang et al.'s model [22] also has the same problem like Sun's model [24] but generally provides better predictions with $R^{2} \approx 0.85$ and $M S E \approx 20$. Xu's model [23] underestimates the ultimate flexural strength of CRC beams like Azad et al.'s model [25], which gives the values of $R^{2}$ around 0.81 and the values of MSE about 30 . These conclusions are generally consistent with previous comparison study, which is shown in Fig. 6.

In summary, among the six empirical models [22-27] for calculating the ultimate flexural capacity of CRC beams, five models $[22,23,25-27]$ underestimate the ultimate flexural capacity of CRC beams, and Sun's model [24] gives an overestimated result. Although these models can predict the ultimate flexural capacity of CRC 


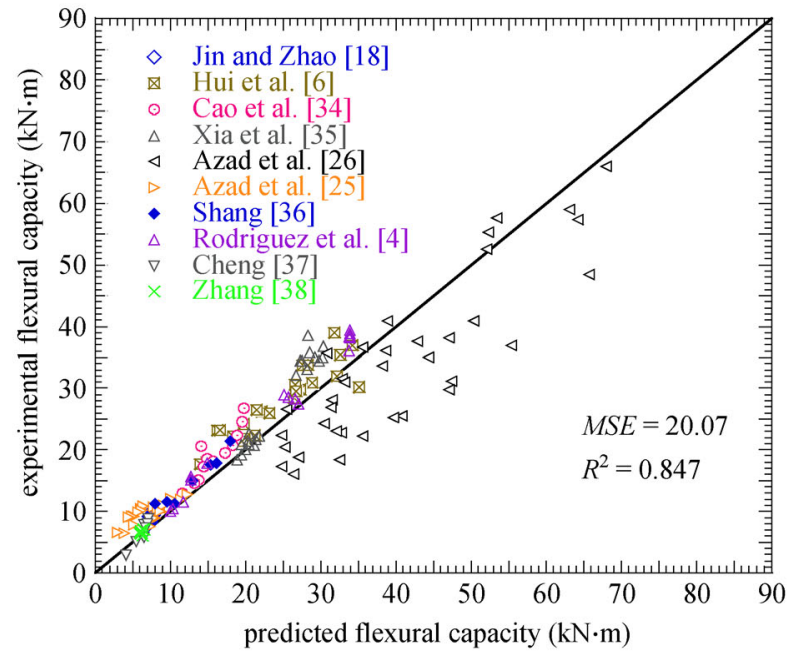

(a)

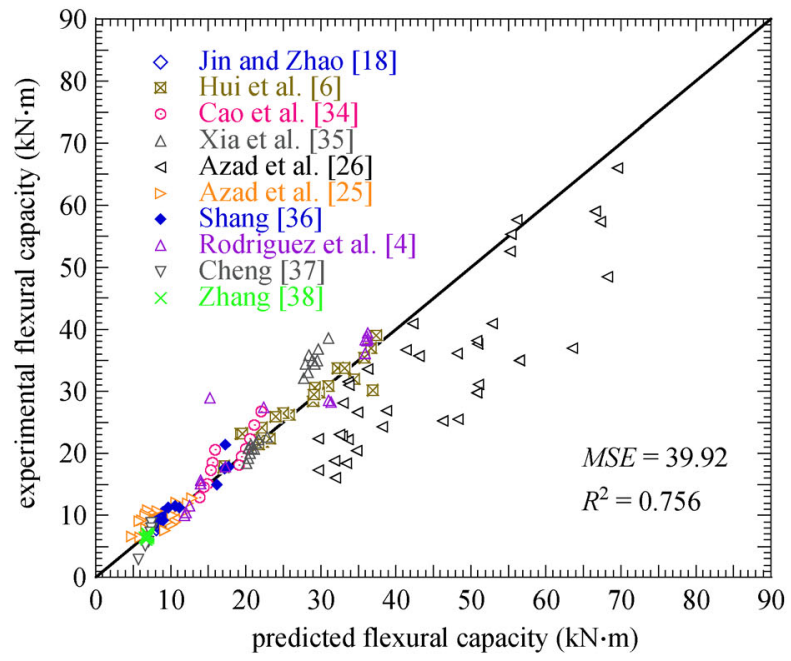

(c)

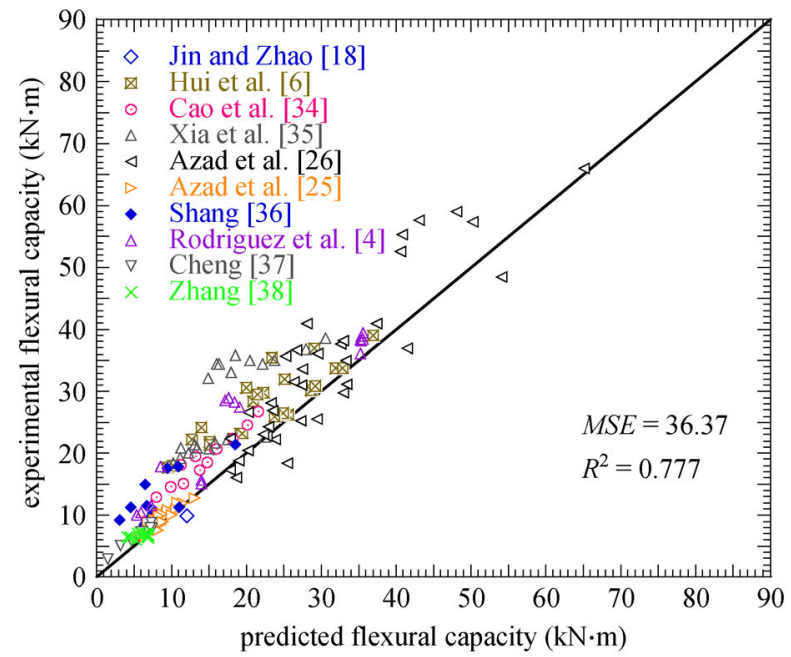

(e)

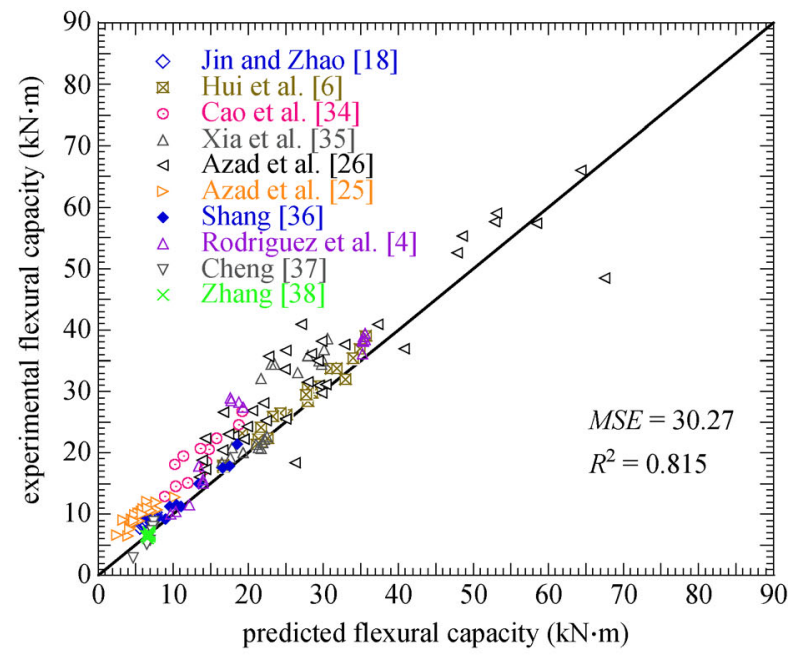

(b)

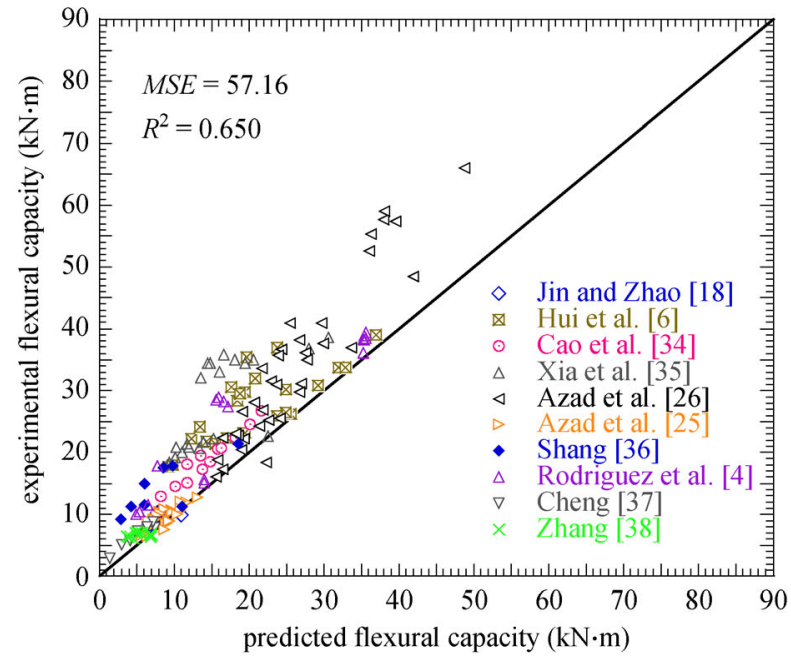

(d)

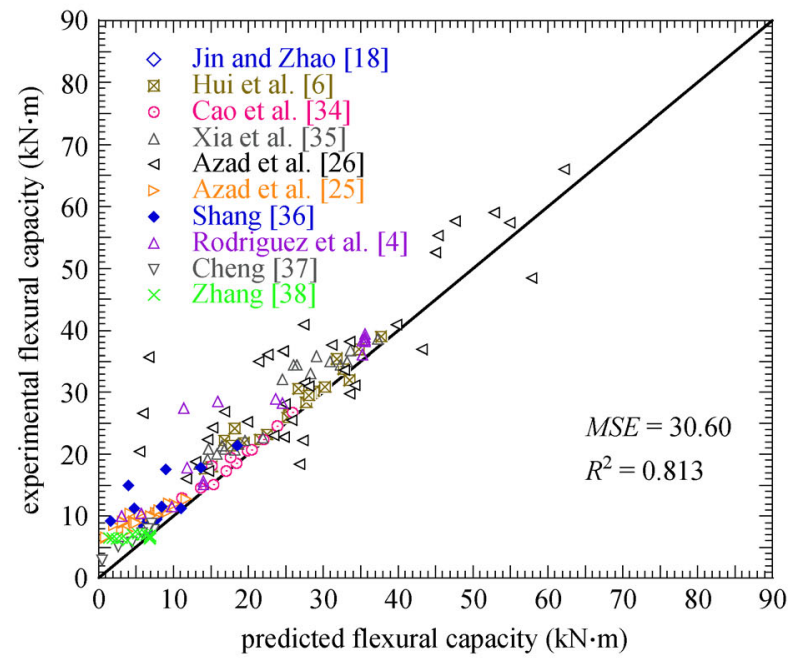

(f)

Fig. 7 The experimental flexural capacity versus the predictions of the existing models. (a) Zhang et al.'s model [22]; (b) Xu's model [23]; (c) Sun's model [24]; (d) Azad et al.'s model [25]; (e) Azad et al.'s modified model [26]; (f) Torres-Acosta et al.'s model [27]. 
beams to a certain extent, it is necessary to propose a new model considering the existing problems and engineering safety issues, which can provide more accurate and effective results.

\section{A new proposed model for flexural capacity of CRC beams}

\subsection{A new empirical model}

The failure mode of the appropriate reinforcement beam is that when the tensile reinforcement reaches yield and compressed concrete reaches ultimate compressive strain simultaneously. However, the failure mode of CRC beams may be altered in consideration of the corrosion impacts $[4,18,22]$. On one hand, due to the decreasing of the crosssectional area and yield strength of the longitudinal reinforcement, the failure mode will be similar to the rare-reinforced beam, which express that when the tensile reinforcement reaching yield strength but the compressed concrete doesn't reach ultimate compressive strain. On the other hand, the bond slip between longitudinal reinforcement and concrete may increase after corrosion and cause uniform strain distribution on the steel. The failure mode is more like the over-reinforced beam, in which the compressed concrete reaches the ultimate compressive strain and meanwhile the tensile reinforcement doesn't reach yield strength. In real progress, the effect of corrosion on the strain of steel bars is dominant, resulting in little probability of the occurrence of the rare-reinforced beam. Thus, CRC beams have two main failure modes: the failure mode of the under-reinforced beam and the failure mode of the over-reinforced beam $[18,22,25,26]$. In other words, concrete in the compression zone can reach the ultimate compressive strain under the limited state of flexural capacity of CRC beams. Also, the load does not directly transfer through the tensile reinforcement, but the bond between the concrete and the steel. Under the limited state of flexural capacity, the bond force provided by the longitudinal reinforcement $\left(F_{\mathrm{tl}}\right)$ can be expressed as [31]:

$$
F_{\mathrm{tl}}=n \times \pi \times D \times l_{\mathrm{a}} \times \bar{\tau}_{\mathrm{u}}\left(\eta_{\mathrm{wt}}\right),
$$

where $n$ is number of the longitudinal reinforcement; $D$ is diameter of the reinforcement; $l_{a}$ is the anchorage length of the longitudinal reinforcement; and $\bar{\tau}_{\mathrm{u}}\left(\eta_{\mathrm{wt}}\right)$ is the average ultimate bond strength at the corrosion level $\eta_{\mathrm{wt}}$. According to Bhargava et al. [31], $\tau_{\mathrm{u}}\left(\eta_{\mathrm{wt}}\right)$ (ultimate bond strength at the corrosion level $\eta_{\mathrm{wt}}$ ) can be expressed as:

$$
\tau_{\mathrm{u}}\left(\eta_{\mathrm{wt}}\right)= \begin{cases}\tau_{\mathrm{u}}(0), & \eta_{\mathrm{wt}} \leqslant 1.5 \%, \\ 1.192 \mathrm{e}^{-0.117 \eta_{\mathrm{wt}}} \cdot \tau_{\mathrm{u}}(0), & \eta_{\mathrm{wt}}>1.5 \%,\end{cases}
$$

where $\tau_{\mathrm{u}}(0)$ is initial ultimate bond strength without corrosion, which can be expressed as follows according to $\mathrm{Xu}[45]$ :

$$
\tau_{\mathrm{u}}(0)=\left(0.82+0.9 D / l_{\mathrm{a}}\right) \times\left(1.9+0.8 c / D+20 \rho_{\mathrm{sv}}\right) \cdot f_{\mathrm{t}},
$$

where $c$ is concrete cover; $\rho_{\mathrm{sv}}$ is the stirrup reinforcement ratio; and $f_{\mathrm{t}}$ is the tensile strength of the concrete.

According to Woo and White [46], for uncorroded beams, the value of the average ultimate bond strength $\bar{\tau}_{\mathrm{u}}(0)$ can be taken as $\frac{1}{2} \tau_{\mathrm{u}}(0)$. Considering the influence of corrosion, the relationship between $\bar{\tau}_{\mathrm{u}}\left(\eta_{\mathrm{wt}}\right)$ and $\tau_{\mathrm{u}}\left(\eta_{\mathrm{wt}}\right)$ can be presented as:

$$
\bar{\tau}_{\mathrm{u}}\left(\eta_{\mathrm{wt}}\right)=\tau_{\mathrm{u}}\left(\eta_{\mathrm{wt}}\right) / m_{\eta_{\mathrm{wt}}},
$$

where $m_{\eta_{\mathrm{wt}}}$ is a correction factor considering the influence of corrosion. Linear interpolation method is adopted when calculating the value of $m_{\eta_{\mathrm{wt}}}$ considering corrosion in this study:

$$
m_{\eta_{\mathrm{wt}}}=2.0-\frac{\eta_{\mathrm{wt}}-\eta_{\mathrm{wt}, 1}}{\eta_{\mathrm{wt}, 2}-\eta_{\mathrm{wt}, 1}},
$$

1) when $\eta_{\mathrm{wt}} \leqslant \eta_{\mathrm{wt}, 1}$, the calculation result of $m_{\eta_{\mathrm{wt}}}$ is taken as 2.0. In this situation, the relationship between $\bar{\tau}_{\mathrm{u}}\left(\eta_{\mathrm{wt}}\right)$ and $\tau_{\mathrm{u}}\left(\eta_{\mathrm{wt}}\right)$ can be expressed as: $\bar{\tau}_{\mathrm{u}}\left(\eta_{\mathrm{wt}}\right)=$ $\frac{1}{2} \tau_{\mathrm{u}}\left(\eta_{\mathrm{wt}}\right)$;

2) when $\eta_{\mathrm{wt}} \geqslant \eta_{\mathrm{wt}, 2}$, the calculation result of $m_{\eta_{\mathrm{wt}}}$ is taken as 1.0. In this case, the relationship between $\bar{\tau}_{\mathrm{u}}\left(\eta_{\mathrm{wt}}\right)$ and $\tau_{\mathrm{u}}\left(\eta_{\mathrm{wt}}\right)$ can be expressed as: $\bar{\tau}_{\mathrm{u}}\left(\eta_{\mathrm{wt}}\right)=\tau_{\mathrm{u}}\left(\eta_{\mathrm{wt}}\right)$;

3) when $\eta_{\mathrm{wt}, 1}<\eta_{\mathrm{wt}}<\eta_{\mathrm{wt}, 2}$, the linear interpolation is adopted to calculate the value of $m_{\eta_{\mathrm{wt}}}$. That is, the relationship between $\bar{\tau}_{\mathrm{u}}\left(\eta_{\mathrm{wt}}\right)$ and $\tau_{\mathrm{u}}\left(\eta_{\mathrm{wt}}\right)$ can be expressed as: $\bar{\tau}_{\mathrm{u}}\left(\eta_{\mathrm{wt}}\right)=\frac{\eta_{\mathrm{wt}, 2}-\eta_{\mathrm{wt}, 1}}{\left(2 \eta_{\mathrm{wt}, 2}-\eta_{\mathrm{wt}, 1}-\eta_{\mathrm{wt}}\right)} \tau_{\mathrm{u}}\left(\eta_{\mathrm{wt}}\right)$.

In engineering practice, with the value of corrosion ratio $\eta_{\mathrm{wt}} \leqslant 5 \%$, the influence of corrosion is ignorable and the average ultimate bond strength is equal to half of the ultimate bond strength. When the value of corrosion $\eta_{\mathrm{wt}}$ is not less than $15 \%$, it can be approximated that the stress in the tensile reinforcement tends to be uniform, so the ratio between the ultimate bond strength and the average ultimate bond strength in the corroded beam is 1.0. Therefore in this study, the values of $\eta_{\mathrm{wt}, 1}$ and $\eta_{\mathrm{wt}, 2}$ are taken as $5 \%$ and $15 \%$, respectively.

When calculating the ultimate flexural capacity of CRC beams, the tensile force $(T)$ generated in the corroded longitudinal reinforcement with the weight loss ratio $\eta_{\mathrm{wt}}$ can be expressed as:

$$
T= \begin{cases}F_{\mathrm{tl}}=n \times \pi \times D \times l_{\mathrm{a}} \times \bar{\tau}_{\mathrm{u}}\left(\eta_{\mathrm{wt}}\right), & F_{\mathrm{tl}} \leqslant f_{\mathrm{yn}} \cdot A_{\mathrm{s}}, \\ f_{\mathrm{yn}} \cdot A_{\mathrm{s}}, & F_{\mathrm{tl}}>f_{\mathrm{yn}} \cdot A_{\mathrm{s}},\end{cases}
$$

where $f_{\mathrm{yn}}$ is nominal yield strength of the longitudinal 
reinforcement after corrosion. According to Lee et al. [47], $f_{\mathrm{yn}}$ can be expressed as:

$$
f_{\mathrm{yn}}=\frac{f_{\mathrm{yc}} \cdot A_{\mathrm{sc}}}{A_{\mathrm{s}}}=\left(1-1.24 \cdot \eta_{\mathrm{wt}}\right) \cdot f_{\mathrm{y}}
$$

where $f_{\mathrm{yc}}$ and $A_{\mathrm{sc}}$ are the yield strength and the effective cross-sectional area of the longitudinal reinforcement after corrosion, respectively.

Conditions of equilibrium of forces must be satisfied, which can be expressed as follows:

$$
\text { Equilibrium of forces : } \Sigma F=0, \alpha_{1} f_{\mathrm{ce}} b x=T \text {. }
$$

The ultimate flexural capacity of the CRC beam can be determined based on the obtained height of the compression zone $x$ :

$$
M_{\mathrm{fx}, \mathrm{cal}}=\alpha_{1} f_{\mathrm{ce}} b x\left(h_{0}-\frac{x}{2}\right)=T\left(h_{0}-\frac{x}{2}\right),
$$

where $M_{\mathrm{fx}, \mathrm{cal}}$ is the ultimate flexural strength at failure of CRC beams; $f_{\text {ce }}$ is the experimental value of concrete prism compressive strength $f_{\mathrm{ck}}$; and $\alpha_{1}$ is coefficient and its value is taken according to GB50010-2002 [33]:

$\alpha_{1}= \begin{cases}1.0, & f_{\mathrm{cu}, 150} \leqslant 50 \mathrm{MPa}, \\ 1.0-0.1\left(f_{\mathrm{cu}, 150} / 50-1\right), & 50 \mathrm{MPa}<f_{\mathrm{cu}, 150} \leqslant 80 \mathrm{MPa},\end{cases}$

This model considers the comprehensive effect of corrosion on flexural capacity of CRC beams, which is developed from the variation of the bond strength between steel and concrete due to the corrosion of steel reinforcement. In the same time, the model comprehensively considers the influence of corrosion on the cross-sectional area, the yield strength of steel bars, and the effect on the bond strength between steel bars and concrete. What's more, the effect of corrosion on beam failure modes has also been considered. The new proposal directly determines the stress of the steel bar under the bending limit state escaping from the cumbersome calculation procedures for obtaining the stress of the steel bar through the deformation coordination condition. Among the six available empirical models listed in this paper, both the models of Zhang et al. [22] and Xu [23] require complex deformation coordination conditions to determine the stress of the steel bar. The calculation result of Sun's model [24] is slightly larger, which may be unsafe for engineering applications. The models of Azad et al. [25,26] and Torres-Acosta et al. [27] consider that the influence of corrosion on the beams is not comprehensive, and does not consider the influence of corrosion from the influence mechanism, but mainly relies on regression analysis, so the calculation results are relatively poor. In summary, the advantage and innovation point of this model is that we can directly determine the stress of the longitudinal reinforcement under the limited state according to the bond of CRC beams. It is unnecessary to use the compatibility of deformations to get the stress of the longitudinal reinforcement at failure of CRC beams like $\mathrm{Xu}$ [23], Zhang et al. [22] and Wang and Liu [1].

\subsection{Verification of the newly proposed model}

For verifying the newly proposed calculation model, Fig. 8(a) shows the calculation results of 177 sets of experimental data in experimental database by the newly proposed model. The abscissa of the graph represents the weight loss ratio of the longitudinal reinforcement, and the ordinate represents the ratio between the test results of ultimate flexural capacity of the CRC beam members and the models' predicted values $\left(M_{\mathrm{fx}, \mathrm{exp}} / M_{\mathrm{fx}, \mathrm{cal}}\right)$. The average, standard deviation, minimum and maximum values, and

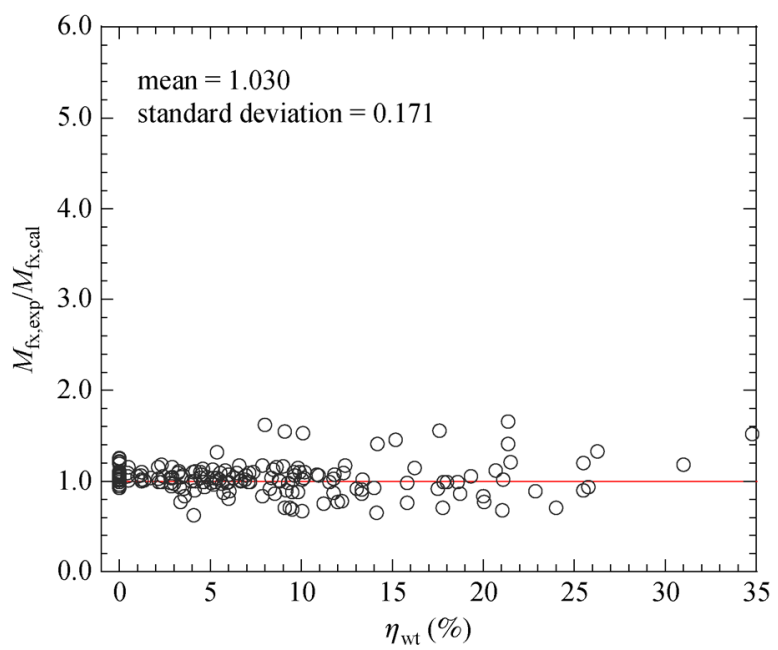

(a)

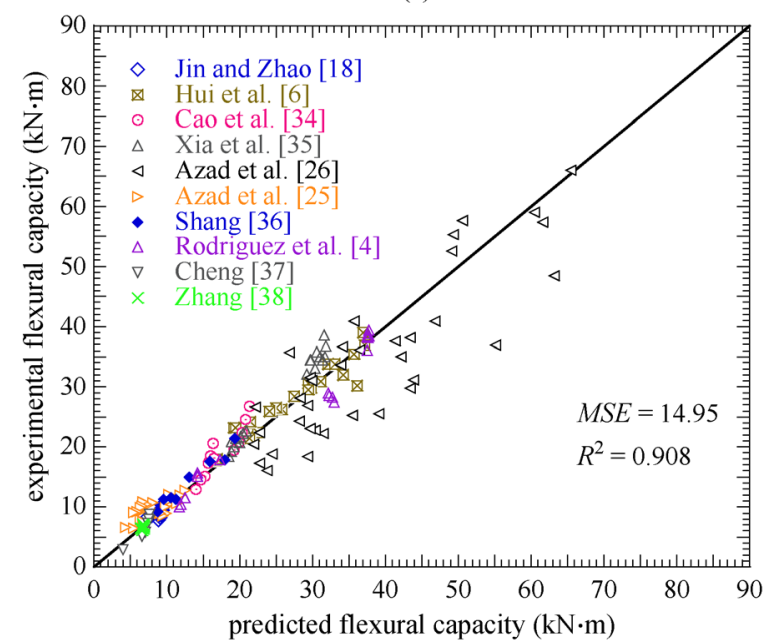

(b)

Fig. 8 Comparisons between experimental results and the predictions of the new proposal. (a) The relationship between $M_{\mathrm{fx}, \exp } / M_{\mathrm{fx}, \text { cal }}$ and $\eta_{\mathrm{wt}}$; (b) The test results versus the predictions. 
the difference between maximum and minimum values of the ratio of all 177 test data are also listed in Table 3. From Fig. 8(a) and Table 3, it is observed that the new proposal can provide an accurate, effective and direct representation of the residual flexural strength of CRC beams, with mean and standard deviation of the ratio of 1.030 and 0.171 , respectively. In addition, Fig. 8 (b) shows the comparison between ultimate flexural capacity of experimental results and the predicted flexural capacity of the calculation model, which includes the values of MSE and coefficient of determination $\left(R^{2}\right)$. It can also be observed from Fig. 8(b) and Figs. 7(a)-7(f) that the newly proposed model can provide better result of prediction for the residual flexural strength of CRC beams than the six empirical models with $R^{2}=0.908$ (the highest one) and $M S E=14.95$ (the lowest one).

Additionally, a sensitivity analysis is conducted to see how the input parameters considered in the new empirical model would affect the models predicted output. For a specific beam, the specific details are marked in the Fig. 9. From Fig. 9 we can observe that when the average ultimate bond strength $\bar{\tau}_{\mathrm{u}}\left(\eta_{\mathrm{wt}}\right)$ varies between $+50 \%$ and $-60 \%$, the flexural capacity of the beam will remain unchanged. This is because the force that the bond strength provides to the steel bar in this state is greater than the yield force of the steel bar, the steel bar can reach its yield strength, and the flexural capacity of the beam is controlled by the yield strength of the steel bar. When the average ultimate bond strength is reduced to $-70 \%$, the flexural capacity of the beam decreases with the decrease of the bond strength, and in this case, when the bond strength is reduced by $10 \%$, the flexural capacity of the beam is reduced by about $20 \%$. This is because in this case, the force that the bond strength provides to the steel bar is less than the yield strength of the steel bar, and the flexural capacity of the beam is controlled by the bond strength. What's more, when the nominal yield strength of the steel bar $f_{\text {yn }}$ decreases by $10 \%$, the flexural

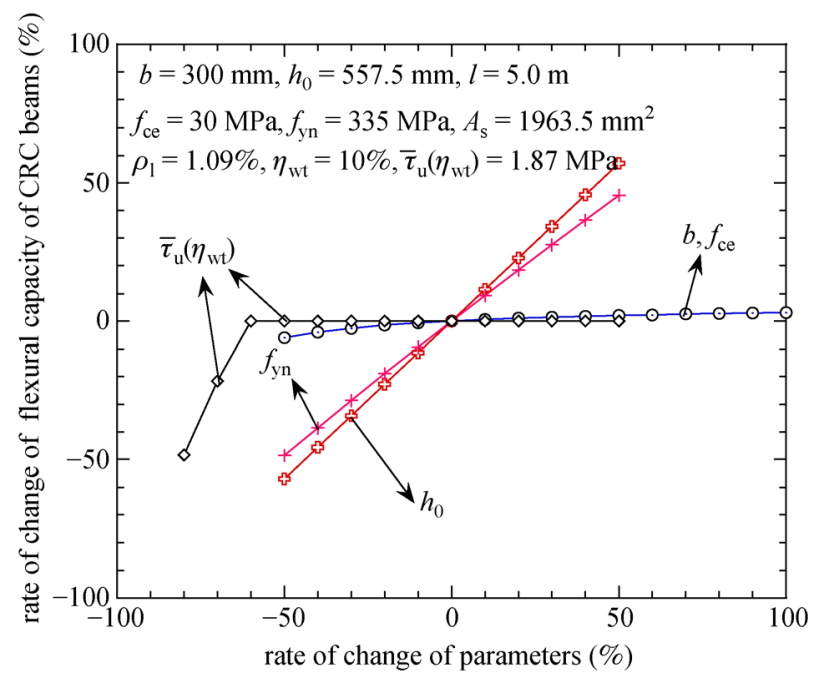

Fig. 9 Sensitivity analysis of the new empirical model. capacity of the beam decreases by about $9 \%$. Because in such a case, the steel bar can reach its yield strength under the limit state, and the flexural capacity of the beam is controlled by the yield strength of the steel bar, which has been mentioned above. If the concrete strength $f_{\text {ce }}$ decreases by $10 \%$, the flexural capacity of the beam decreases by $0.6 \%$. Compared with the concrete strength, the beam width $b$ has the same effect on the flexural capacity of the beam because their status is consistent according to Eqs. (12) and (13). If the effective height of the test beam $h_{0}$ decreases by $10 \%$, the flexural capacity of the beam decreases by about $11 \%$. The decrease trend is close to linear, which can be explained by Eq. (13). Thus, it can be seen that under the premise of the same crosssectional area, increasing the beam height can significantly increase the flexural capacity of the beam, which is consistent with the actual project.

\subsection{The limitations of the new proposal}

As observed from the investigation above, only strength of the concrete is considered as the indicator of concrete's quality and utilized in the new proposal for the prediction of the residual flexural capacity of corroded reinforced concrete beams. Nowadays, the UHPC, HPC, SCC, and other innovations in concrete mix designs are widely applied to the construction of RC structures, and the influence of concrete mixes on the structural behavior of CRC beams may be different due to the difference in bond strength, permeability and so on. However, the effect of concrete mixes was not considered in this study. Moreover, in the engineering practice, most beam structures work with cracks, and the residual flexural capacity of beams is also affected by the long-term creep of concrete [48,49]. However, this study did not consider the coupling effect of long-term load, crack and corrosion.

In addition, for prestressed reinforced concrete (PRC) beams, the situation is different from ordinary RC beam. First, most of the longitudinal reinforcement material of PRC beams is steel strand. The mechanical properties and surface conditions of steel strands are different from those of ordinary steel bars, which lead to different effects of corrosion on steel bars. Additionally, in the pre-tensioned PRC beams, the force between steel strands and the concrete is in a state of high bond stress for a long time and the distribution of bond stress along steel strands is different and complex [50]. For post-tensioned PRC beam, the bonding mechanism between steel strands and cement paste is different from ordinary RC beams. And the presence of the bellows also complicates the bond between steel strands and the cement paste. In addition, for all PRC beams, the coupling effect between corrosion and prestress needs to be considered. The effect of corrosion on PRC beam is more complicated. Therefore, the new model proposed at present may not be directly applied to PRC beams. However, this study still provides an insight into 
the flexural capacity of corroded prestressed concrete beams.

\section{Conclusions}

In this study, total 177 sets of experimental data for CRC beams of flexural tests were collected in the published literatures. The influence of several parameters on the residual flexural strength of CRC beam was analyzed, and six available empirical models [22-27] proposed by various studies are evaluated to investigate their applicability and accuracy for predicting the residual flexural capacity of CRC beams. Based on the investigations, a new empirical model is proposed. The main conclusions and contributions are summarized as follows.

1) Compared to other parameters (beam section size, ratio of strength between longitudinal reinforcement and concrete, and concrete compressive strength), longitudinal reinforcement corrosion ratio exhibit the highest effect on the residual flexural strength of CRC beams.

2) According to the results of established database of flexural tests, five of the six empirical models $[22,23,25-$ 27] underestimate the ultimate flexural capacity of CRC beams ranging from $77.4 \%$ to $92 \%$ lower than the flexural test results, while Sun's model [24] provides the overestimated results.

3) A new model for calculating the residual flexural strength of ordinary CRC beams is proposed in this study, which considers the effect of failure modes. Based on the bonding degradation model, the ultimate flexural capacity of CRC beams can be obtained when the tensile force of steel bar in limited state is confirmed.

4) The comparisons between the experimental results and the predictions of the new proposal demonstrate that the proposed empirical model can provide an accurate and effective prediction for the residual flexural strength of CRC beams within a large range of corrosion degree.

5) The new proposed model can be applied to predict the flexural capacity of CRC beams with acceptable accuracy, providing an insight into the way for the service life prediction and safety assessment of corrosion-induced flexural failure of RC structures.

6) It should be noted that the new empirical model has some limitations: the effect of concrete mixes on the behavior of CRC beams was not considered; moreover, this study did not consider the coupling effect of long-term load, crack and corrosion. Further study is needed with the consideration of these effects on the modeling of the residual flexural capacity of CRC beams.

Acknowledgements The authors acknowledge the research supports from the National Natural Science Foundation of China (Grant Nos. 51820105014, 51738001, U1934217) and the research funds from Australian Research Council (DE150101751) and ARC Industrial Transformation Research Hub Component Project "Nano-geopolymer composites for underground prefabricated structures" with Wuhan Zhihe Geotechnical Engineering Co., Ltd.
The authors are also grateful for the financial supports of the University of Technology Sydney Research Academic Program at Tech Laboratory (UTS RAPT) and University of Technology Sydney Tech Laboratory Blue Sky Research Scheme.

\section{References}

1. Wang X H, Liu X L. Simplified methodology for the evaluation of the residual strength of corroded reinforced concrete beams. Journal of Performance of Constructed Facilities, 2010, 24(2): 108-119

2. Mehta P K. Durability of concrete-Fifty years progress. ACI Special Publication, 1991, 126(1): 1-32

3. Almusallam A A, Al-Gahtani A S, Aziz A R, Dakhil F H, Rasheeduzzafar. Effect of reinforcement corrosion on flexural behavior of concrete slabs. Journal of Materials in Civil Engineering, 1996, 8(3): 123-127

4. Rodriguez J, Ortega L M, Casal J. Load carrying capacity of concrete structures with corroded reinforcement. Construction \& Building Materials, 1997, 11(4): 239-248

5. Mangat P S, Elgarf M S. Flexural strength of concrete beams with corroding reinforcement. ACI Structural Journal, 1999, 96(1): 149158

6. Hui Y L, Li R, Lin Z S, Quan M Y. Experimental studies on the property before and after corrosion of rebars in basic concrete members. Industrial Construction, 1997, 27(4): 14-18 (in Chinese)

7. Huang R, Yang C C. Condition assessment of reinforced concrete beams relative to reinforcement corrosion. Cement and Concrete Composites, 1997, 19(2): 131-137

8. Lu Z H, Ou Y B, Zhao Y G, Li C Q. Investigation of corrosion of steel stirrups in reinforced concrete structures. Construction \& Building Materials, 2016, 127: 293-305

9. Jnaid F, Aboutaha R S. Residual flexural strength of corroded reinforced concrete beams. Engineering Structures, 2016, 119: 198216

10. Torres-Acosta A A, Sagues A A. Concrete cracking by localized steel corrosion-Geometric effects. ACI Materials Journal, 2004, 101(6): 501-507

11. Zhu W J, Francois R. Corrosion of the reinforcement and its influence on the residual structural performance of a 26-year-old corroded RC beam. Construction \& Building Materials, 2014, 51: $461-472$

12. Stewart M G. Mechanical behaviour of pitting corrosion of flexural and shear reinforcement and its effect on structural reliability of corroding RC beams. Structural Safety, 2009, 31(1): 19-30

13. Dekoster M, Buyle-Bodin F, Maurel O, Delmas Y. Modelling of the flexural behaviour of RC beams subjected to localised and uniform corrosion. Engineering Structures, 2003, 25(10): 1333-1341

14. O'Flaherty F J, Mangat P S, Lambert P, Browne E H. Effect of under-reinforcement on the flexural strength of corroded beams. Materials and Structures, 2008, 41(2): 311-321

15. Malumbela G, Moyo P, Alexander M. Behaviour of RC beams corroded under sustained service loads. Construction \& Building Materials, 2009, 23(11): 3346-3351

16. Bhargava K, Ghosh A K, Mori Y, Ramanujam S. Ultimate flexural 
and shear capacity of concrete beams with corroded reinforcement. Structural Engineering and Mechanics, 2007, 27(3): 347-363

17. Fan Y F, Zhou J, Feng X. Prediction of load carrying capacity of corroded reinforced concrete beam. China Ocean Engineering, 2004, 18(1): 107-118

18. Jin W L, Zhao Y X. Test study on bending strength of corroded reinforced concrete beams. Industrial Construction, 2001, 31(5): 9 11 (in Chinese)

19. Al-Sulaimani G J, Kaleemullah M, Basunbul I A. Rasheeduzzafar, Influence of corrosion and cracking on bond behaviour and strength of reinforced concrete members. ACI Structural Journal, 1990, 87(2): 220-231

20. Castel A, Francois R, Arliguie G. Mechanical behaviour of corroded reinforced concrete beams-Part 2: Bond and notch effects. Materials and Structures, 2000, 33(9): 545-551

21. Jin W L, Zhao Y X. Effect of corrosion on bond behavior and bending strength of reinforced concrete beams. Journal of Zhejiang University. Science A, 2001, 2(3): 298-308

22. Zhang J R, Zhang K B, Peng H, Gui C. Calculation method of normal section flexural capacity of corroded reinforced concrete rectangular beams. China Journal of Highway and Transport, 2009, 22(3): 45-51 (in Chinese)

23. $\mathrm{Xu} \mathrm{S} \mathrm{H.} \mathrm{The} \mathrm{deteriorated} \mathrm{models} \mathrm{and} \mathrm{durability} \mathrm{evaluation} \mathrm{of}$ reinforced concrete structure. Dissertation for the Doctoral Degree. Xi'an: Xi'an University of Architecture and Technology, 2003 (in Chinese)

24. Sun B. Structural performance degrading and seismic evaluation of existing reinforced concrete structures. Dissertation for the Doctoral Degree. Xi'an: Xi'an University of Architecture and Technology, 2006 (in Chinese)

25. Azad A K, Ahmad S, Azher S A. Residual strength of corrosiondamaged reinforced concrete beams. ACI Materials Journal, 2007, 104(1): 40-47

26. Azad A K, Ahmad S, Al-Gohi B H A. Flexural strength of corroded reinforced concrete beams. Magazine of Concrete Research, 2010, 62(6): 405-414

27. Torres-Acosta A A, Navarro-Gutierrez S, Terán-Guillén J. Residual flexure capacity of corroded reinforced concrete beams. Engineering Structures, 2007, 29(6): 1145-1152

28. Cabrera J G, Ghoddoussi P. The effect of reinforcement corrosion on the strength of the steel/concrete bond. In: Proceedings of the International Conference on Bond in Concrete, from Research to Practice. Riga, Latvia: Riga Technical University, 1992, 11-24

29. Ting S C, Nowak A S. Effect of reinforcing steel area loss on flexural behavior of reinforced-concrete beams. ACI Structural Journal, 1991, 88(3): 309-314

30. Lu Z H, Lun P Y, Li W G, Luo Z, Li Y, Liu P. Empirical model of corrosion rate for steel reinforced concrete structures in chlorideladen environments. Advances in Structural Engineering, 2019, 22(1): 223-239

31. Bhargava K, Ghosh A K, Mori Y, Ramanujam S. Corrosion-induced bond strength degradation in reinforced concrete-Analytical and empirical models. Nuclear Engineering and Design, 2007, 237(11): $1140-1157$

32. BIS. 2000. IS: 456, Indian Standard Code of Practice for Plain and Reinforced Concrete. 4th Revision. New Delhi: Bureau of Indian
Standards, 67-76

33. GB50010-2002. Code for Design of Concrete Structures. Beijing: China Building Industry Press, 2002 (in Chinese)

34. Cao F B, Wang C X, Liu L G, Xin Y D, Li J H, Tian Z G. Experimental study and rigidity analysis on corroded reinforced recycled concrete beams. Building Structure, 2015, 45(10): 49-55 (in Chinese)

35. Xia J, Jin W L, Li L Y. Effect of chloride-induced reinforcing steel corrosion on the flexural strength of reinforced concrete beams. Magazine of Concrete Research, 2012, 64(6): 471-485

36. Shang D F. Study on flexural behavior of corroded reinforced concrete beams. Dissertation for the Doctoral Degree. Shanghai: Tongji University, 2005 (in Chinese)

37. Chen J. Study on degradation regularity of bearing capacity of RC beams under corrosive conditions. Journal of Disaster Prevention and Mitigation Engineering, 2013, 33: 83-87 (in Chinese)

38. Zhang Z. Experimental study of bending behavior of corroded reinforced concrete beams. Dissertation for the Doctoral Degree. Shanghai: Shanghai Jiao Tong University, 2010 (in Chinese)

39. MacGregor J G. Reinforced Concrete: Mechanics and Design. 3rd ed. New Jersey: Prentice Hall, 1997

40. Lu Z H, Li H, Li W G, Zhao Y G, Dong W K. An empirical model for the shear strength of corroded reinforced concrete beam. Construction \& Building Materials, 2018, 188: 1234-1248

41. Eurocode 2. Design of concrete structures - Part 1-1: General Rules and Rules for Buildings. EN 1992-1-1. Brussels: European Committee for Standardization, British Standards Institution, 2004

42. Day R L, Haque M N. Correlation between strength of small and standard concrete cylinders. ACI Materials Journal, 1993, 90(5): 452-462

43. Rashid M A, Mansur M A, Paramasivam P. Correlations between mechanical properties of high-strength concrete. Journal of Materials in Civil Engineering, 2002, 14(3): 230-238

44. Wang X H, Zhong T Y. Relation between the loss coefficient of the corroded rebar's cross-section in concrete and that of its weight. Research and Application of Building Materials, 2005, 1: 4-6 (in Chinese)

45. Xu Y L, Shao Z M, Shen W D. Bond strength between reinforcing bars and concrete. Building Science, 1988, 4(4): 8-14 (in Chinese)

46. Woo K, White R N. Initiation of shear cracking in reinforced concrete beams with no web reinforcement. ACI Structural Journal, 1991, 88(3): 301-314

47. Lee H S, Noguchi T, Tomosawa F. FEM analysis for structural performance of deteriorated RC structures due to rebar corrosion. In: Proceeding of the 2nd International Conference on Concrete Under Severe Conditions. Tromso: CRC Press, 1998, 327-336

48. Koh C G, Ang K K, Zhang L. Effects of repeated loading on creep deflection of reinforced concrete beams. Engineering Structures, 1997, 19(1): 2-18

49. Zhang L, Mendis P, Hon W C, Fragomeni S, Lam N, Song Y. Effect of cyclic loading on the long-term deflection of prestressed concrete beams. Computers and Concrete, 2013, 12(6): 739-754

50. Wang L, Zhang X H, Zhang J R, Dai L Z, Liu Y M. Failure analysis of corroded PC beams under flexural load considering bond degradation. Engineering Failure Analysis, 2017, 73: 11-24 